\title{
Perceptions of Canadian Federal Policy Responses to COVID-19 among People with Disabilities and Chronic Health Conditions
}

\section{David Pettinicchio}

Associate professor of sociology and Munk School of Global Affairs and Public Policy, University of Toronto, Toronto, Ontario, Canada

\section{Michelle Maroto}

Associate professor of sociology, University of Alberta, Edmonton, Alberta, Canada

\section{Martin Lukk}

PhD candidate, sociology, University of Toronto, Toronto, Ontario, Canada

This study examines how people with disabilities and chronic health conditions - members of a large and diverse group often overlooked by Canadian public policy — are making sense of the Canadian federal government's response to COVID-19. Using original national online survey data collected in June $2020(\mathrm{~N}=1,027)$, we investigate how members of this group view the government's overall response. Although survey results show broad support for the federal government's pandemic response, findings also indicate fractures based on disability type and specific health condition, political partisanship, region, and experiences with COVID-19. Among these, identification with the Liberal party and receipt of CERB stand out as associated with more positive views. Further examination of qualitative responses shows that these views are also linked to differing perspectives surrounding government benefits and spending, partisan divisions, as well as other social and cultural cleavages.

Keywords: COVID-19, disability, health, political partisanship, federal government Mots clés : COVID-19, personnes handicapées, santé, partisanerie politique, gouvernement fédéral 


\section{Introduction}

Canadian policy responses to the COVID-19 pandemic are generally thought to have been swifter, more consistent, more widely-implemented, better informed by health experts, and more cautious towards recovery than many other countries. Success has been attributed to a centralized rapid response facilitated by cross-partisan cooperation among federal and provincial leaders (Mignone 2020; see also Howlett and Mignone 2019).

Despite Canada's early reputation as having successfully responded to the pandemic (Miller 2020; Roser et al. 2020; Wilson et al 2020), the public's views of the federal policy response vary across the country. Along with regional differences, individual experiences with COVID-19 and political preferences shape perceptions of the pandemic and the government's response to it. These responses include social distancing policies undertaken to address COVID-19's spread that ranged from closures and lockdowns to mask-wearing mandates and public handwashing campaigns. They also include early and swift income support polices, such as the Canada Emergency Response Benefit (a.k.a., CERB), meant to address the economic impacts of COVID-19 on the public at large. With these policies in place, not to mention variation in provincial discourse around the pandemic response, there was considerable variation in Canadians' confidence in the federal government's handling of the pandemic - from believing the government has not done enough to believing it has gone too far. 
Although regional and partisan differences in support for the government's response to COVID19 are expected, members of different marginalized groups may also experience and respond to policy differently. This study focuses on the views of people with disabilities and chronic health conditions - a large marginalized group that already experiences significant employment and financial barriers, as well as obstacles to accessing social and health services. As the pandemic unfolded, the disproportionate impacts of the virus and the corresponding social distancing measures on already vulnerable and economically marginalized groups across Canada became increasingly apparent. This was especially true for people with different disabilities and chronic health conditions. The ways social, political, and economic factors affect people with disabilities and chronic health conditions are made ever more acute in times of crises given that health and disability status are key determinants of individuals' experiences and life chances. A diverse community, it is also likely that policy perceptions vary within and among people with different disabilities and chronic health conditions.

Based on original data from a national online survey of 1,027 people with disabilities and chronic health conditions conducted in June 2020, we address several key questions. How do people with disabilities and chronic health conditions view the federal government's response to COVID-19? Does support vary by specific disability and condition? Is it connected to experiences with COVID-19? What other factors does support vary by including partisan preferences and regionality? 
Our results contribute to the evolving understanding of the ways in which public policy responses

to global health pandemics impact already vulnerable populations. We find that people with disabilities and chronic health conditions have been generally supportive of the federal government's response to COVID-19 with $45 \%$ of respondents reporting positive ratings. However, respondents' perceptions about the virus and about public policy responses also largely varied by disability type and health status, partisan political preferences, and region, illustrating that people with disabilities and chronic health conditions, often treated as a single homogenous group, are diverse in their public policy preferences. Although we expected respondents to view the pandemic through a lens heavily informed by their experiences with disability and health, and potentially membership in other status groups, we found that support was much more connected to larger political views and individual experiences with the virus itself.

We begin with a general discussion of the ways in which pre-existing structural disadvantage is tied to disability and health status and the potential ways COVID-19 policy responses have exacerbated extant inequalities. We specifically outline how people with disabilities and chronic health conditions have been affected by COVID-19 and measures taken to combat its deleterious effects. We then discuss how extant disadvantage, experiences with COVID, regionality and partisan political preferences shape public perceptions of federal government pandemic responses.

\section{Extant Inequality and Pandemic Policy Responses}


Pandemics are shocks to the system. Although they may generate new forms of disadvantage and inequality, they often amplify existing structural inequalities. Policy contexts play an important role in determining whether pre-existing levels of inequality will increase during and following pandemics, shaping how different segments of society experience these crises and post-crisis recovery. In that vein, the COVID-19 pandemic has highlighted policy shortcomings (Arcaya et al. 2020) and revealed the kinds of cumulative vulnerabilities that place certain groups like disabled people and people with pre-existing chronic health issues in greater social, health, and economic jeopardy (Olsson 2015; Fothergill and Peek 2015; Hoffman et al. 2020). Social scientists studying health have long pointed out that pre-existing inequalities based on group status characteristics directly and indirectly determine health and other outcomes (Link and Phelan 1995, 2005; Morey 2018). This situation is no different.

\section{Disability-Based Economic Inequality}

As axes of inequality, disabilities and chronic health conditions are associated with low employment rates and earnings (Blanck et al. 2007; Maroto and Pettinicchio 2014a, 2015; Maroto, Pettinicchio and Patterson 2019). Importantly, existing research shows considerable variation in employment outcomes depending on the nature of the disability. Individuals with cognitive disabilities are far more likely to experience negative labor market outcomes than individuals with respiratory and heart problems and physical disabilities (Jones 2011; Zwerling et al 2002).

A major reason for poor labour market outcomes among people with disabilities is that they are disproportionately clustered in low-paying, precarious, nonstandard work, often in the food 
preparation and service industries (Maroto and Pettinicchio 2014b; Morris et al. 2018; Shuey and Jovic 2013). Workers with cognitive and multiple disabilities are most likely to be employed in these kinds of jobs while those with sensory limitations are least likely (Maroto and Pettinicchio 2014b; Pettinicchio and Maroto 2020; Wall 2017). The pandemic has most severely affected sectors that people with disabilities tend to work in and, as a result, particularly harmed workers who were already struggling with low earnings and financial insecurity (Mather and Jarosz 2020).

Canadian households who count a member with a disability have less wealth and hold far fewer non-home assets than those without a disability (Maroto 2016; Maroto and Pettinicchio 2020a). Many of these individuals live on the poverty line and cannot rely on savings in times of crises. This likely varies by the type and severity of disability as these shape access to appropriate care and social supports that facilitate maintaining steady income and covering higher costs of living. Over one million Canadians are registered with the Disability Tax Credit (DTC), which covers only a subset of disabled Canadians and is often required to access products like the Registered Disability Savings Plan (RDSP) meant to mitigate financial insecurity. About $40 \%$ of individuals registered with DTC list mental functional limitations and many on DTC for an indeterminate time are experiencing difficulties in daily independent living activities. ${ }^{1}$ Although RDSPs are meant to encourage savings, program rules have been criticized for having the opposite effect and for assuming individuals with few financial resources have any money to save.

\section{COVID-19 Policy Responses}

\footnotetext{
${ }^{1}$ https://www.canada.ca/content/dam/cra-arc/prog-policy/stats/dtc-stats/DTC-2018-tbl8-2018_e.pdf
} 
As British Columbia, Alberta, Québec, and Ontario saw a rapidly increasing number of COVID19 cases in March 2020 (The Canadian Press 2020a), the federal government sought to address threats to healthcare system capacity (The Canadian Press 2020b), embarked on massive national information dissemination campaigns about the virus and ways to reduce risk, including new protective and social distancing measures, and promised direct financial aid to Canadians, namely via the taxable wage subsidy known as the Canada Emergency Response Benefit (a.k.a., CERB).

CERB, which was extended twice throughout the spring and summer of 2020, was limited to employed Canadians who had lost all or some income as a direct result of COVID-19. This means that individuals, including many people with disabilities and others with chronic health conditions, already struggling to find work before the pandemic, could not benefit from CERB (Leoppky 2020). In the fall, CERB was rolled into Employment Insurance offering Canadians a credit of insured hours but this again remained problematic for the many disabled Canadians who did not previously qualify for CERB. Instead, federal economic policies meant to aid Canadians with disabilities during the pandemic have been relying on enhanced Goods and Services Tax (GST) payments to cover rising costs. More recently, those with a valid DTC certificate were automatically issued a one-time non-taxable $\$ 600$ payment. In July, the government expanded this program to include an additional 1.7 million Canadians with disabilities who either already receive a CPP disability benefit or disability supports through Veterans Affairs Canada (Government of Canada 2020b). 
The continuously unfolding pandemic raises the issue of how changing policy responses and programmatic rules are understood among already vulnerable groups who not only face a higher risk of getting the virus, but also face uncertain economic futures. Disadvantaged groups including people with disabilities and chronic health conditions do not have equal access to health resources, social programs, and financial information (Chen et al. 2018; Pennycook et al. 2020; Van Rooij, Lussardi and Alessie 2011) which influences how they perceive policy responses.

\section{Varying Attitudes Towards Policy Responses}

Although most Canadians support most measures taken to combat the coronavirus (Maru/Blue Public Opinion 2021), policy responses to the pandemic in Canada have fundamentally restricted everyday life activities, posing greater limitations for certain groups that no doubt affect how individuals view government. Views regarding any government's response to COVID-19 will likely vary across factors that include a person's specific situation and demographics, their existing partisan beliefs, and their experiences with the pandemic. Although together they compose one of the groups most vulnerable to the virus, people with disabilities and chronic health conditions include a broad range of individuals with different disabilities, health conditions, demographics, and political perspectives. We examine variability in attitudes towards COVID-19 policy responses based on specific disabilities and health conditions, experiences with COVID-19, and broader partisan views and regional differences. 


\section{Disability and Health Status During the Pandemic}

Varying disability and health statuses shape experiences with and attitudes about government institutions and policy. In addition to being left out of income support programs (Shakeri 2020), individuals with respiratory issues, those who experience debilitating panic attacks, people on the autism spectrum, and people who rely on lip-reading to effectively communicate experienced significant problems adhering to protective guidelines and were provided with few resources and guidelines by public officials (The Canadian Press 2020c; Aslam, Hall, and the Canadian Press 2020). Against a backdrop of the crisis still unfolding in long-term care facilities, many people with more severe disabilities who require in-home visits from care workers were not receiving those supports (see Choi 2020) and social distancing and isolation measures have increasingly been shown to have deleterious effects on individuals already struggling with health and mental health issues (Vigo et al 2020; Emerson et al 2020). As such, attitudes towards COVID-19 policy responses reflect extant experiences under new and continuously unfolding health and socioeconomic scenarios.

Perceptions of policy fairness, whether about disparate impacts of social distancing measures or economic impacts and burdens unduly placed on those already financially strained, have direct bearing on public attitudes about government responses and subsequent public action (Han and Zheng 2020). Individuals struggling economically because of their health and disability status tend to have more negative perceptions of policy because they see themselves as victims of unjust inequalities (Mattila 2020; see also Corcoran, Pettinicchio and Young 2011; 2015). Social distancing, protective and lock down measures, as well as being left out of income support 
programs could be seen as imposing unequal burdens and as ignoring already economically vulnerable groups. This may shape short and long-term policy perceptions and attitudes towards government (Mattila 2020).

\section{Political Partisanship and Regional Variation}

Public perceptions are also shaped by how Canadian policymakers collectively frame and define rapidly unfolding issues (Mignone 2020; Howlett and Mignone 2019; Pettinicchio 2017; 2019) and the ways in which these are communicated. They may signal consensus around providing income supports (which in the case of CERB led to a swift government response), but disagreement in how to approach lockdowns. The extent to which officials appear to be transparent, clear, and consistent with their messaging shapes public attitudes (Mohammed et al. 2020; Driedger, Maier and Jardine 2018; Quinn et al. 2013; Taha et al 2013). Merkeley et al. (2020) described a "crosspartisan consensus" among Canadian political elites that explains a lack of partisanship among public attitudes and behaviours. In this vein, COVID-19 is thought to be largely apolitical in Canada, where no one party challenged policies but, rather, rallied around the role of experts from the start.

Nonetheless, Pennycook and colleagues (2020) show that partisan attitudes significantly shaped how Canadians responded to the pandemic and to policies meant to address it. And, even Merkeley et al. (2020) found a relationship between party affiliation and perceptions of severity in Canada, where Conservatives viewed the pandemic as less severe. However, Bol et al. (2020) found that 
pandemic-related lockdowns increased support for those in power and confidence in government perhaps because the public saw the government taking necessary measures to keep citizens safe.

Recent studies have focused on consensus among political elites (Pennycook et al 2020; Merkeley et al 2020) but this cross-partisanship may not neatly overlap with partisan differences in how the Canadian public assesses federal government responses to the pandemic. This potential disconnect between elite and public policy preferences may reflect growing political polarization among the Canadian public more generally (Pettinicchio 2010; Cochrane 2015). Kevin and Soroka (2018) show that partisan sorting on attitudes about redistribution in Canada has increased substantially over the past two decades. In addition, deep historical regional divisions are clearly embodied within the newly formed "Wexit" or "Maverick" party, pushing for Western Canadian sovereignty (Dryden 2020). Regional divides are especially evident in Québec and in Prairie provinces, which further complicate the link between public preferences and government responses to the pandemic (Baer, Grabb, and Johnston 1993; Wiseman 2007).

Thus, while health pandemics can act as critical moments in shifting public perceptions about politics and policy translating these attitudes into actions and behaviours (Merkeley et al 2020; Liu and Mehta 2020), individuals still draw from personal experiences and long held partisan preferences in understanding pandemic policy responses. With that, we examine support for overall federal government responses to COVID-19 among people with disabilities and chronic health conditions, a diverse but marginalized group that tends to be underrepresented in public policy research. We focus on differences by disability and condition type, political affiliation, 
region, and experiences with COVID-19 to better understand how each of these factors can drive public perceptions of government policy and policymakers in times of crisis.

\section{Data}

Data come from a quota-based online survey administered from June 11 to June 22, 2020, just as many cities and provinces across Canada were beginning to end their "lockdowns" and "open up" their economies. ${ }^{2}$ We relied on Qualtrics, an internet-based survey research company that uses paid panels of respondents, to help obtain a sample of people with disabilities and health conditions across the country. In addition to payment received from the survey company, we provided respondents with additional \$10 Amazon.ca gift cards.

The survey includes 1,027 respondents age 18 and older who reported having one or more disabilities or health conditions. Disabilities include physical, cognitive, vision, hearing, and emotional limitations based on a set of six questions. We also included a category related to "other" conditions lasting six months or longer. To gauge the severity of different disabilities, respondents were given options of answering, "never," "sometimes," "often," or "always" to each of these questions. Health conditions include asthma, cancer, chronic kidney disease, chronic respiratory disease, diabetes, heart disease, hypertension, obesity, and being immunocompromised. Questions asking about disability were based on the Canadian Survey on Disability (Cloutier, Grondin, and

\footnotetext{
2 As of June 22, 2020, there were 101,019 confirmed COVID-19 cases in Canada and 8,410 deaths with both cases and deaths trending downward across the country (https://covid19.who.int/region/amro/country/ca).
} 
Levesque 2018) and guidance provided by the World Health Organization and the Washington Group on Disability Statistics. ${ }^{3}$ Health conditions were chosen based on those indicated by the Government of Canada as increasing vulnerability to COVID-19 (Government of Canada 2020c).

Data were collected via quota-based sampling to ensure that we obtained a representative sample across provinces with 38\% of responses from Ontario, 23\% from Québec, 13\% from British Columbia, 18\% from the Prairie provinces (Alberta, Manitoba, Saskatchewan), and 7\% from the Atlantic provinces (Newfoundland and Labrador, New Brunswick, Nova Scotia, and Prince Edward Island) based on 2016 Census population estimates (Statistics Canada 2017). We choose not to include any other characteristics within our quotas or weight our data after collection. In particular, we do not use poststratification, a weighting method commonly used when analyzing data from web-based surveys to adjust for under-coverage, nonresponse, and self-selection in the sample (Bethlehem 2010; Schonlau et al. 2009). This method uses auxiliary information on true population values, from census data or probability-based surveys, to generate weights that can be applied to each respondent in a web-based survey so that the sample as a whole better represents the population. However, this procedure requires the distribution of characteristics in a population to be known. In our case, it was unclear on which population characteristics we should base any weights since there have been no other random surveys of individuals with disabilities and chronic health conditions. However, many of the characteristics of this group (e.g., age, gender, and education) mirror those for individuals sampled in the Canadian Survey on Disability and the

\footnotetext{
${ }^{3}$ http://www.washingtongroup-disability.com, see also Pettinicchio and Maroto on measuring disability (2021, forthcoming).
} 
Canadian Community Health Survey. We note such comparisons in the discussion of our descriptive statistics. Please see Appendix A for a descriptive overview of our sample and Appendix B for a comparison to the 2017-18 CCHS data.

\section{Measures and Methods}

We analyze respondents' views of the federal government's response to COVID-19 as our key outcome variable. Specifically, respondents were asked "In general, how would you rate the federal government's response to COVID-19?" We asked respondents to provide a rating on a scale of $0-10$ ( 0 being the lowest, 10 being the highest) and then further elaborate on that rating in an open-ended question. We combined results into the three following categories: negative assessment (score of 0-4), neutral assessment (score of 5-7), and positive assessment (score of 8$10)$.

We then analyzed this outcome using a set of multinomial logistic regression models. ${ }^{4}$ Multinomial models expand on basic logistic regression models to allow for the inclusion of outcome variables with multiple categories. Within these models, the probability of membership in each category is compared to the probability of membership in a designated reference category (Liao, 1994; Menard, 2002). ${ }^{5}$ Additionally, by interpreting our results as average marginal effects

\footnotetext{
${ }^{4}$ We tested other combinations of categories, as well as a series of logit and linear models, and found similar relationships across variables. Results are available in the online appendix.

${ }^{5}$ Ordered logistic regression models present another alternative for analyzing ordered categorical data. However, these models assume that the relationship between each pair of outcomes is the same (proportional odds assumption) and initial model tests showed that our data violated this assumption. We therefore chose the more flexible
} 
and predicted probabilities, we are able to show the estimated difference in the probability of reporting the specified level of support for government responses when considering all other options. Standard errors account for clustering by province. All models include demographic and economic control variables. ${ }^{6}$

Our first set of predictor variables focuses on variation by disability and chronic health condition type. ${ }^{7}$ We include variables for six disabilities. The first four measure whether the respondent reported having any difficulty seeing (even when wearing glasses or contact lenses); hearing (even when using a hearing aid); walking, using stairs, using your hands or fingers or doing other physical activities; and learning, remembering or concentrating. Two other variables measure whether the respondent reported any emotional, psychological or mental health conditions and any other health problems or long-term conditions that have lasted or are expected to last for six months or more. Disability-related questions also allowed respondents to indicate the severity of their disability by responding "never," "sometimes," "often," or "always." We focus on more severe disabilities and code respondents who indicated they often or always experienced the outcomes as reporting that disability.

We classified chronic health conditions based on whether the respondent indicated the presence of the nine following conditions: Asthma; Cancer; Chronic kidney disease; Chronic respiratory or

multinomial logistic regression model for our analyses. Ordinal logistic regression results are available in the online Appendix C.

${ }^{6}$ Demographic controls include age, gender, race, parental and marital status, and education. We also controlled for employment status and homeownership.

${ }^{7}$ Descriptive statistics for these variables appear in Appendix A. 
lung disease; Diabetes; Hypertension; Heart disease; Immunocompromised; or Obesity. Answers were obtained from a single question, worded as: "Do you presently have any of the following health conditions? Please mark all that apply."

Our second set of predictor variables focus on political partisanship and region. Political party includes four categories for the major political parties: Liberal Party (referent), Conservative Party, New Democratic Party, and Other or No Party. ${ }^{8}$ Province/region includes categories of Ontario (referent), Québec, British Columbia, Prairie Provinces (Alberta, Manitoba, and Saskatchewan), and Atlantic Provinces (Newfoundland and Labrador, New Brunswick, Prince Edward Island, and Nova Scotia). ${ }^{9}$

To assess experiences with COVID-19 in a third set of predictor variables, we include a series of composite variables measuring COVID-19 expenses, informed about COVID-19, and concerned about COVID-19. Composite variables combine the results of multiple variables measured on the same or similar scales, facilitating comparison. We use a process of meaningful grouping and averaging. We also include dichotomous variables measuring whether the respondent applied for $C E R B$ and whether a respondent's financial situation has worsened during the pandemic.

COVID-19 expenses is a composite variable assessing the economic effects of COVID-19 on the respondent's finances. It comprises responses to the following five questions: "Since COVID-19

\footnotetext{
${ }^{8}$ The "Other or No Party" categories includes respondents who listed parties with smaller membership, such as the Green Party, the People's Party, and Bloc Québécois, as well as respondents who indicated "Other party" or no preference.

${ }^{9}$ We grouped smaller provinces together due to sample size limitations.
} 
restrictions have been put in place, have you had to (a.) spend from savings to make ends meet, (b.) use credit cards for essential expenses, (c.) take out loans to pay for essential expenses, (d.) contact a financial institution to request mortgage or loan payment deferrals, and (d.) rely on government programs like, but not exclusively, CERB to make ends meet." Values for the composite variable are the respondent's average across these questions, which we measured as binary $(0=$ no, $1=$ yes $)$ responses with $\alpha=0.664$.

The COVID-19 information composite variable assesses how informed the respondent is about COVID-19. It includes responses to the following four questions: "How informed do you believe you are about (a.) access to COVID-19 testing, (b.) how to get treatment for COVID-19, (c.) COVID-19 symptoms, and (d.) what to do if you suspect you have COVID-19." Original variable values were uniformed (0), somewhat informed (1), and very informed (2). Composite variable scores are the respondent's averages with $\alpha=0.797$.

The COVID-19 concerned variable includes responses for the following seven questions: "How concerned are you with (a.) contracting COVID-19 yourself, (b.) a friend or family member contracting COVID-19, (c.) paying your bills, (d.) keeping your job, (e.) finishing your degree, (f.) accessing healthcare, and (g.) shopping for essential goods. Original variable values were not concerned (0), somewhat concerned (1), and very concerned (2). Composite variable scores are the respondent's averages with $\alpha=0.799$. 
In addition to our quantitative ratings of federal government responses to COVID-19, we also analyzed qualitative responses to an open-ended survey question asking respondents to explain why they provided the ratings they did. Specifically, respondents were asked "Why did you select that score?" after choosing a rating. We inductively coded responses to these open-ended questions and identified emergent themes associated with reasons respondents gave for their quantitative assessments of policy responses. We also linked the codes associated with respondents' qualitative responses to their demographic and attitudinal characteristics to help contextualize their reasoning.

\section{Findings}

We found broad support for the federal government's response to COVID-19. Most respondents thought that the federal government was doing a good job addressing the pandemic. As shown in Table 1, the average score for the federal government was 6.84 with $13.24 \%$ of respondents rating their response negatively, $42.06 \%$ giving it a neutral rating, and $44.69 \%$ giving it a positive rating. Examining differences across key variables shows a potential relationship with some disabilities and chronic health conditions. Scores also tended to be lower among respondents affiliated with the Conservative Party, those living in the Prairie provinces, and those who reported worsening financial situations.

\section{[Table 1]}


When asked why they provided a certain rating, most individuals did not elaborate upon their quantitative assessments of government responses to COVID-19. Many qualitative responses involved restating a numerical assessment in words without any further elaboration, as in the case of statements like "The government is doing [a] very good job," "Sickening Response," and "I think the job they did was fine but it should have been a lot better." Other respondents framed their assessments in terms of preconceived expectations of how the government would handle a pandemic although not necessarily referring to any specific government policy or action. Their responses encompassed a range from "seems like they could be doing more" to "surprisingly great."

Importantly, some respondents indicated that they were unable to provide further justification because they admittedly lacked knowledge about government responses. Statements like, "I do not [know] enough about what the government is doing in this case to make a comment" and "I don't follow the news" point to attitudes and beliefs that cannot be readily articulated. This suggests that respondents not only lacked specific information about government actions related to COVID-19 even in the most general sense but that, relatedly, their assessments may be based on other kinds of information including pre-existing beliefs about government, partisan preferences, and their own experiences throughout the pandemic.

Table 2 presents the results from multinomial logit models predicting respondents' views of the federal government's response to COVID-19. We report model coefficients as average marginal effects for each of the three categories of negative, neutral, or positive. Coefficients can be 
interpreted as a percentage point change in the probability of falling into the specified category associated with a change in the specified predictor variable. Original model coefficients are available in Appendix C.

\section{[Table 2]}

Results in Table 2 show that respondents' support for the federal government's response to COVID19 was largely driven by partisanship, region, and COVID-19 experiences with a few differences by disability and chronic health condition type. We therefore focus our interpretation on these variables and further illustrate these results in Figures 1,2, and 3. These figures plot the predicted probabilities of reporting a negative, neutral, or positive response associated with different levels of these key predictor variables. Figure 1 includes disability and health condition, Figure 2 includes partisan preferences and region, and Figure 3 includes COVID-19 experiences. Categories are listed for categorical variables. Three levels of low, mean, and high are listed for the continuous variables. These refer to values at the mean and one standard deviation above and below the mean. Results come from models with all control variables.

[Figure 1]

[Figure 2]

[Figure 3] 


\section{Type of Disability and Chronic Health Condition}

Comparing results by specific disabilities and chronic health conditions, Table 2 and Figure 1 show that there is not much variation in support for the federal government's response to COVID-19 across these variables. However, a few groups do stand out. People with physical disabilities tended to view the government response more positively than people with other types of disabilities. For instance, only $7.4 \%$ reported a negative response, compared to $10-22 \%$ of people reporting other disabilities. Percentages with a positive response, however, were more similar across disabilities. In terms of health conditions, people with chronic kidney conditions, diabetes, or cancer were the least likely to report a negative response.

Qualitative responses provide limited insight into the reasons behind observed differences in support between these disability groups. Respondents generally did not explain their assessments with reference to their disability or health status, suggesting that these were not key considerations when evaluating government responses. Occasionally, however, justifications referenced vulnerable groups seen as having received insufficient attention and support. In these comments, respondents discussed how the government had not done enough to help vulnerable Canadians, including those with disabilities. Numerous respondents mentioned that existing supports were not helping everyone in need, "insufficient," and constituted a poorly thought out "patchwork" of programs. 


\section{Political Partisanship and Region}

Specific partisan differences were most evident when considering negative responses in Table 2. Compared to respondents who identified with or supported the Liberal Party, Conservative Party supporters were 26.0 percentage points more likely to have a negative assessment of the federal government's response, NDP members were 5.9 percentage points more likely, and members of other parties were 12.3 percentage points more likely. Conservative Party supporters were also 36.6 percentage points less likely to have positive responses.

Comparing political parties in Figure 2, Liberals were the most likely group to provide a positive assessment of the federal government's response, perhaps not surprisingly with a Liberal minority government led by Justin Trudeau. Conservatives stood out with the greatest proportion having a negative response; $19.4 \%$ rated the federal government negatively compared to $3-9 \%$ of Liberals and NDP members. Conservatives were also much less likely to have a positive response with $23.8 \%$ rating the government positively.

Across regions, the Prairie provinces stood out as having lower ratings of the federal government's response to COVID-19. Respondents in the Prairie provinces were 3.2 percentage points more likely to provide a negative response and 8.7 percentage points less likely to give a neutral response, but they were also 5.5 percentage points more likely to provide a positive response than those in Ontario (Table 2). Overall, $16.1 \%$ of Prairie residents rated the response as negative. However, the significant difference here was with those reporting neutral responses; $35.0 \%$ of 
respondents in the Prairies provided a neutral response compared to $42-45 \%$ among the other provinces, suggesting more polarized views of the federal government in that region.

Open-ended responses provided further insight into how partisanship shapes attitudes about the federal response to COVID-19, with fewer patterns present across regions. Although some respondents, mostly those identifying with the Conservative Party, expressed concerns about policies limiting basic freedoms and that the pandemic is being blown out of proportion, these were a very small minority.

Rather, quite common among negative assessments was the belief that federal economic responses to COVID-19 constituted an irresponsible, wasteful use of taxpayer money that would add too much to the federal budget deficit. A familiar "small-c" conservative critique of "small-l" liberal fiscal policies, this kind of response was especially common among respondents who identified with the Conservative Party. Criticisms from Conservative respondents regularly implicated Prime Minister Justin Trudeau directly: "the PM keeps giving away money that the country does not have," "I haven't been impressed with the way Justin has been throwing money around with no real oversight" and "Trudeau has gone crazy giving away so much money." Concerns about spending, the deficit and the fear of higher taxes in the future were expressed by members of other parties as well.

More specifically, Conservative respondents also expressed concern that federal funds were being used to pay benefits to those who did not qualify or were otherwise undeserving. For example, 
even though CERB is taxable income, one respondent explained, "They've been doing a decent job however they have mismanaged the CERB in giving the same amount to everyone and not taxing it. People who should be receiving the base amount of EI are making twice as much and those who should be receiving the max aren't getting that much. And there are many who are getting it that shouldn't be." Concerns about CERB were not limited to Conservative respondents. Some worried about lack of accountability and that CERB serves as a disincentive to work.

However, negative assessments among non-Conservatives also emphasized gaps in existing benefit programs when it comes to seniors and people with disabilities. For example, a Liberal respondent noted that the federal government has "made strides to support people that have been economically affected by COVID-19, though the benefits seem to be a little bit scattershot at times." Expressing overall support for federal government responses, a respondent identifying with none of the main federal parties wished "they'd done more for the elderly and disabled. A one-time payment simply isn't enough. Everything is becoming more and more expensive." Much more critical, an NDP supporter wrote that "The government failed in supporting vulnerable people. The pandemic shows that the system is rigged in favour of the wealthy."

Negative assessments among respondents identifying as Conservative reflect long-standing conflicts with Liberals, and in some cases, Trudeau himself. Conservative respondents in particular frequently emphasized the theme of government overreach. For example, respondents often expressed concern that the Liberal government used the existing state of emergency granting government temporary emergency powers as a means to encroach on civil liberties and further 
their own political aims. As one respondent declared, “...they also seem to be circumventing our political system to do as they please with no opposition."

Conservative respondents were also more likely to tie current social and cultural issues, like gun rights, police funding, and Black Lives Matter, into their negative assessments. A few respondents specifically cited Trudeau's appearance at an anti-racism demonstration ${ }^{10}$ on Parliament Hill coinciding with large-scale protests in cities in the United States in the wake of the police killing of George Floyd. As one respondent phrased it, "Over the top and double standards. People protest losing their jobs [and] gov[ernment] says they're irresponsible but [at] BLM protest some even broke windows in Canada and our PM takes a knee in a crowd." Another respondent specifically describing Trudeau's appearance at the demonstration wrote that it "is a disgrace to all my brothers in blue." Playing on the broader belief that the Liberals have used the crisis to "seize total control," a respondent identifying with the far-right populist People's Party in their assessment referred to "a totally unjust and nonsensical gun ban by order in council."

When it comes to partisan preferences, our findings indicate that for the most part, Conservatives, who were by far the most critical of the federal Liberal government's response to the pandemic, drew upon pre-existing political conflicts but also on salient cultural and social cleavages in justifying their criticism. Liberals and especially NDP supporters also expressed negative

\footnotetext{
${ }^{10}$ During a moment of silence at the demonstration, Trudeau, wearing a mask, was seen bowing his head and dropping to one knee in an expression of solidarity with the protest movement.
} 
assessments but these were more often framed in terms of socio-economic inequalities in the pandemic response and critiques of benefits going to landlords and large corporations.

\section{COVID-19 Experiences}

Respondents' perceptions of the federal government's response were also shaped by their understandings of, and experiences with, COVID-19. Differences across these variables, however, were most apparent when considering how informed respondents felt about COVID-19, as shown in Table 2. A one-unit increase in how informed respondents were about COVID-19 was associated with a 4.0 percentage point decrease in rating the government's response negatively, a 12.1 percentage point decrease in giving a neutral rating, and a 16.1 percentage point increase in rating the government's response positively.

Figure 3 shows that feeling informed about COVID-19 was also associated with attitudes about the federal government's response in different ways. The proportion of respondents rating the government negatively decreased from $15.1 \%$ to $11.1 \%$ when moving from low to high levels of feeling informed. Differences were even more apparent when comparing other categories. For instance, $36.6 \%$ of people reporting low levels of information around COVID-19 rated the federal government's response positively compared to $52.6 \%$ of those with high levels of information. Thus, those who felt more informed about COVID-19 also thought that the government was doing a better job of addressing it. 
Although reporting specific-COVID-19-related expense increases was not associated with views, reporting worsening financial situations was. Respondents who experienced financial hardship in the previous year were also more likely to rate the government's response negatively by 3.8 percentage points and less likely to rate it positively by 7.6 percentage points (Table 2 ). These differences translated into $15.4 \%$ of respondents with worsening finances reporting negative views, $44.4 \%$ reporting neutral views, and $40.1 \%$ reporting positive views (Figure 3 ).

In addition, benefits receipt was positively associated with support for the federal government's response. Respondents who applied for CERB were more likely to rate the government's response positively by 8.1 percentage points and less likely to provide a negative rating by 5.4 percentage points than those who had not applied for CERB (Table 2). According to Figure 3, 50.1\% of respondents who applied for CERB rated the government's response as positive, 39.8\% rated it as neutral, and $9.2 \%$ rated it as negative.

In their qualitative responses, individuals regularly discussed their perceptions of the federal government with reference to their own experiences, especially in receiving government supports, most notably CERB. One respondent expressed overall approval of government benefit programs while being unhappy about their own experience with receiving benefits: "The federal government did what was required in the immediate wake of the crisis, and despite the fact that I do not qualify for CERB, its rollout was quick and effective for most of Canada... yeah, I'm still grumpy about the CERB thing." Indeed, those who rated the federal response positively also regularly referenced their experiences with benefit receipt as a justification, as in the case in this response: “... the 
CERB program was excellent and made me able to cope throughout these tough times. I am very pleased [with] my government services.”

Others, who gave neutral ratings, also discussed their own and others' experiences with CERB, pointing out issues they saw in its implementation. One respondent indicated that "CERB is good but it should be based on income and expenses, not just a general number everyone gets. Some people live rent-free while others (like me) have to use almost the whole benefit for living expenses, so I think it could be a little more equitable." Respondents who held more negative perceptions of federal government responses linked these to their inability to make ends meet despite government benefits as a rationale. For example, one senior wrote that "when you have high drug expenses and rent to pay the money they've promised doesn't go very far. And the money they promised which should have been paid out at the beginning of June has now been pushed back to sometime in July." Others similarly noted insufficient support provided by benefits: "my husband's income dropped by more than $25 \%$ and there was no help for him... and CERB paid me less than EI."

The variation in perceptions about federal government responses suggests that individuals who are benefitting from CERB are likely having more of their needs met, feel more financially secure, and thus have more favourable attitudes about government. On the flip side, our findings suggest that these policy responses are not meeting the needs of all Canadians - especially people with disabilities and chronic health conditions who are not benefitting from CERB and are facing a host of different social, economic, and health-related challenges during the pandemic. 


\section{Discussion}

This study examined relationships between respondents' reported disabilities and chronic health conditions, partisanship, regionality, and experiences with COVID-19 and their views of the federal government's response to COVID-19. We focused on an already disadvantaged group in Canadian society - people with disabilities and chronic health conditions. Despite these vulnerabilities, this group was largely ignored by policymakers until about three months into the pandemic. Even so, when it comes to federal financial support, the vast majority of people with disabilities and chronic health conditions who are not benefitting from CERB continue to be excluded from aid programs. As we find, experiences with COVID-19 among these individuals mattered a great deal in shaping perceptions of government responses. However, our findings also point to broader factors, as political preferences tended to be a stronger predictor of support for federal government responses to the crisis. Indeed, our findings show that respondents' support for government responses was highly partisan. Our findings are corroborated by more recent public opinion polls, like ones conducted in Alberta, for example, where satisfaction with federal government responses showed significant splintering along party lines (Fletcher 2020).

Some of the largest differences were seen between respondents affiliated with the Liberal and Conservative parties, with Liberals voicing the most support and Conservatives voicing the least. As the qualitative responses demonstrate, part of this was driven by broader political views surrounding government spending likely to be the case in the general population as well. Our 


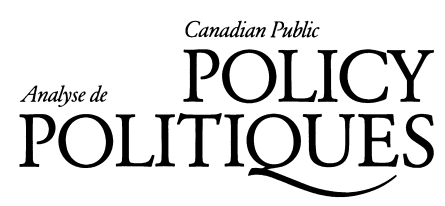

This article has undergone peer review and been accepted for publication by the Canadian Public Policy/Analyse de politiques. Due to the importance of the subject matter, and the rapidly changing nature of the topic, the accepted version has been released. A final, copyedited and formatted version will be published at a later date.

findings reveal that while political elites by and large demonstrated consensus around how to respond to COVID-19, thus transcending party lines, the public displayed stronger views, a lot of which reflect traditional left-right divides over government spending and who is most "deserving" of government benefits. Although it is among those who believe governments have gone too far where we saw the most partisan responses, Liberal and NDP supporters also noted that too many vulnerable people are being excluded from government programs.

Future work should investigate these claims at the provincial level, linking partisan preferences to perceptions of provincial government responses where many more governments are led by Conservatives. Our findings indicate more nuanced relationships between party affiliation and support for provincial government responses to the pandemic, where Conservatives in provinces with Conservative governments are still more critical of their government than Liberals. Some of this may be attributable to concerns over spending even by Conservative-led governments as well as significant social distancing measures enacted by Conservatives in provinces like Ontario, for example.

We presented findings from one of the few national Canadian surveys that focuses on people with disabilities and chronic health conditions. Due to many of the larger limitations regarding survey research today, including underrepresentation of marginalized communities, quota sampling is extremely useful in studying the immediate effects of health crises on people with disabilities and chronic health conditions. Although quota sampling is not truly reflective of a random sample of the population, our sample does mirror the demographic characteristics of members of the target 
population of interest which in this case, is Canadians with disabilities and chronic health conditions, as discussed in the Appendix. However, this online survey likely missed many people without access to computers or the Internet. Results still provide us with considerable understanding of individuals' experiences and views regarding government responses to COVID19 , giving voice to a group that is often overlooked in politics and policymaking.

\section{Conclusion}

Policy preferences among people with disabilities and chronic health conditions reflect broader partisan divides, as well as health and economic situations specific to this group. Our paper alludes to how this plays out in relation to support for federal government responses to the COVID-19 crisis. Although respondents mentioned feeling left out and overlooked - "we are the forgotten," as one respondent put it - perceptions of government responses were less directly driven by respondents' status as people with disabilities or as having chronic health conditions and more by partisan divisions and broader social, economic, and cultural cleavages (Harell 2020). However, disability and health status may be having indirect effects on attitudes about government via personal experiences with COVID-19, which include financial concerns, barriers in accessing health and social services, and worries about what the so-called "new normal" will look like for them.

Our paper speaks to current considerations but it also alludes to long-term implications both with regards to health and financial wellbeing and with perceptions of government policy and 
policymakers. The pandemic is ever-evolving. What many respondents have voiced is that effective policy pandemic countermeasures should include targeted efforts to help disadvantaged groups in addition to broader efforts in addressing social conditions shaping experiences during and post-crisis. Policymakers have long recognized that the needs of persons with disabilities are often overlooked during disasters and emergencies and ensuing recovery efforts. Canada and others have affirmed their commitment to take disability-related needs into account in all disasterrelated policies and practices through international agreements including the United Nations Convention on the Rights of Persons with Disabilities and Sendai Framework for Disaster Risk Reduction 2015-2020. In this regard, policy experts are calling for permanent income supports targeting disability and health groups (Prince 2020), paralleling similar calls to institutionalize CERB into a universal basic income for all (Snell 2020; Willms and Montgomery 2020). Whatever the case, when it comes to recovery, exclusion should not be the "new normal."

\section{Acknowledgements}

Data collection for this project was funded in part by a Social Science and Humanities Research Council of Canada Insight Grant, Ottawa, Ontario, Canada (\#498400) as well as an Ontario Ministry of Research and Innovation Early Researcher Award Grant, Toronto, Ontario, Canada (\#502347). The plan for this study was reviewed and approved by a Research Ethics Board at the University of Alberta (REB Ethics ID Pro00101049) and at the University of Toronto (protocol reference number 39352). 


\section{References}

Arcaya, M., Raker, E.J., \& Waters, M.C. 2020. “The social consequences of disasters: Individual and community change.” Annual Review of Sociology 46 (1): 11.1-11.21.

Aslam, S., M. Hall, \& The Canadian Press. 2020. Canada's top doctor hearing reports of maskshaming. CityNews, May 29, 2020. https://edmonton.citynews.ca/2020/05/28/canadastop-doctor-hearing-reports-of-mask-shaming/.

Baer, D., Grabb, E., \& Johnston, W.A. 1993. "National character, regional culture, and the values of Canadians and Americans." Canadian Review of Sociology 30(1): 13-36.

Bethlehem, Jelke. 2010. "Selection Bias in Web Surveys." International Statistical Review 78(2):161-88.

Blanck, P., Adya, M., Myhill, W.N., Samant, D., \& Chen, P. 2007. "Employment of People with Disabilities: Twenty-Five Years Back and Ahead." Law and Inequality, 25(2): 323-354.

Bol, Damien, Marco Giani, André Blais and Peter Loewen. 2020. "The effect of COVID-19 lockdowns on political support: Some good news for democracy?" European Journal of Political Research doi: 10.1111/1475-6765.12401 
Chen, Xuewei, Jennifer L. Hay, Erika A. Waters, Marc T. Kiviniemi, Caitlin Biddle, Elizabeth Schofield, Yuelin Li, Kimberly Kaphingst \& Heather Orom. 2018. "Health Literacy and Use and Trust in Health Information." Journal of Health Communication 23(8): 724-734.

Choi, Sannah. 2020. "Why COVID-19 has personal support workers feeling uneasy during homecare visits.” CBC News, April 4, 2020. https://www.cbc.ca/news/canada/toronto/whycovid-19-has-personal-support-workers-feeling-uneasy-during-home-care-visits-

\section{$\underline{1.5520722}$}

Cloutier, E., C. Grondin, \& A. Lévesque. 2018. "Canadian Survey on Disability, 2017: Concepts and methods guide." Statistics Canada, Catalogue no. 89-654-X2018001 ISBN 978-0-66027535-2.

Cochrane, Christopher. 2015. Left and Right: The Small World of Political Ideas. Montreal and Kingston: McGill-Queen's University Press.

Corcoran, Katie E., David Pettinicchio and Jacob T. N. Young. 2011. "The context of control: A cross-national investigation of the link between political institutions, efficacy, and collective action." British Journal of Social Psychology 50(4): 575-605. 
Corcoran, Katie E., David Pettinicchio and Jacob T. N. Young. 2015. "Perceptions of Structural Injustice and Efficacy: Participation in Low/Moderate/High-Cost Forms of Collective Action." Sociological Inquiry 85(3): 429-461.

Driedger, S. M., R. Maier, and C. Jardine. 2018. "Damned If You Do, and Damned If You Don't': Communicating about Uncertainty and Evolving Science during the H1N1 Influenza Pandemic." Journal of Risk Research 17 (7): 1-19

Dryden, J. 2020. Wexit political party can now run candidates in Canadian federal elections. CBC News, Jan. 11, 2020. https://www.cbc.ca/news/canada/calgary/wexit-peterdowning-western-separatism-elections-canada-1.5423793

Emerson, E., Fortune, N., Llewellyn, G., \& Stancliffe, R. 2020. Loneliness, social support, social isolation and wellbeing among working age adults with and without disability: Cross sectional study. Disability and Health Journal, 14(1) doi.org/10.1016/j.dhjo.2020. 100965.

Fletcher, R. 2020. "Most Albertans approve of government responses to COVID-19, but 'political lens' skews our views." CBC News, June 15. Accessed 10 Sept. https://www.cbc.ca/news/canada/calgary/alberta-poll-covid-government-handlingpandemic-approval-1.5608611. 
Fothergill, Alice and Lori Peek. 2015. Children of Katrina. Austin: University of Texas Press

Government of Canada. 2020a. Minister Qualtrough announces new details on proposed

financial support for persons with disabilities during COVID-19. Employment and Social

Development Canada News Release, July 17, 2020.

https://www.canada.ca/en/employment-social-development/news/2020/07/x.html

Government of Canada. 2020b. Vulnerable populations and COVID-19. Public Health Agency of Canada. https://www.canada.ca/en/public-health/services/publications/diseasesconditions/vulnerable-populations-covid-19.html

Han, Qing, Bang Zheng, Mioara Cristea, Maximilian Agostini, Jocelyn Belanger, Ben Gutzkow, Jannis Kreienkamp, et al. 2020. "Trust in Government and Its Associations with Health Behaviour and Prosocial Behaviour During the COVID-19 Pandemic." PsyArXiv June 29. doi:10.31234/osf.io/p5gns.

Harell, A. 2020. "How Canada's pandemic is shifting political views." Report for the Institute for Research on Public Policy. Available at https://policyoptions.irpp.org/fr/magazines/avril-2020/how-canadas- pandemic-responseis-shifting-political-views/ 
Hoffman JS, Shandas V, Pendleton N. 2020. "The effects of historical housing policies on resident exposure to intra-urban heat: a study of 108 US urban areas." Climate 8(1):12.

Howlett, M., \& Migone, A. 2019. "Over-promising and under-delivering: The Canadian policy style." In Policy styles and policy making: Exploring the linkages, edited by M. Howlett \& J. Tosun, 137-156. London: Routledge.

Kevins, A., \& Soroka, S. N. 2018. "Growing apart? Partisan sorting in Canada, 1992-2015.” Canadian Journal of Political Science 51(1):103-133.

Leoppky, J. 2020. When collecting CERB means losing disability benefits. Briarpatch Magazine, July 2, 2020. https://briarpatchmagazine.com/saskdispatch/view/whencollecting-cerb-means-losing-disability-benefits

Liao, T.F. 1994. Interpreting probability models: Logit, probit, and other generalized linear models. Thousand Oaks, CA: Sage.

Link, B. G. and J. Phelan. 1995. "Social Conditions and Fundamental Causes of Disease." Journal of Health and Social Behavior 35:80-94.

Link, B. G., \& Phelan, J. C. 2005. "Fundamental sources of health inequalities.” In Policy 
challenges in modern health care, edited by D Mechanic, LB Rogut, DC Colby and JR Knickman, 71-84. New Brunswick, NJ: Rutgers University Press.

Liu, Brooke F. and Amisha M. Mehta 2020. "From the periphery and toward a centralized model for trust in government risk and disaster communication.” Journal of Risk Research, DOI: $10.1080 / 13669877.2020 .1773516$.

Maroto, Michelle and David Pettinicchio. 2014a. "The Limitations of Disability Antidiscrimination Legislation: Policymaking and the Economic Well-being of People with Disabilities." Law \& Policy, 36(4): 370-407.

Maroto, M., \& Pettinicchio, D. 2014b. "Disability, structural inequality, and work: The influence of occupational segregation on earnings for people with different disabilities." Research in Social Stratification and Mobility 38: 76-92.

Maroto, Michelle and David Pettinicchio. 2015. "Twenty-Five Years After the ADA: Situating Disability in America's System of Stratification.” Disability Studies Quarterly 35(3): 134.

Maroto, M., Pettinicchio, D., \& Patterson, A. 2019. "Hierarchies of Categorical Disadvantage: Incorporating Disability into Intersectional Analyses of Economic Insecurity." Gender \& Society 33(1): 64-93. 
Maroto, M., \& Pettinicchio, D. 2020. "Barriers to Economic Security: Disability, Employment, and Asset Disparities in Canada." Canadian Review of Sociology, 57(1):53-79.

Maru/Blue Public Opinion. 2021. “Support for Pandemic Lockdown Rules.” Jan. 9. https://www.marublue.com/canadian-polls/support-for-pandemic-lockdown-rules.

Mattila, Mikko. 2020. "Does poor health mobilize people into action? Health, political trust, and participation?” European Political Science Review 12(1): 49-65.

Mather, Mark and Beth Jarosz. 2020. "Workers at Risk During the Coronavirus Pandemic: Four in 10 Food Preparers and Servers Are Low-Income.” Population Reference Bureau https://www.prb.org/workers-at-risk-during-the-covid-19-pandemic-four-in-10-foodpreparers-and-servers-are-low-incomel

Menard, S. 2002. Applied logistic regression analysis, $2^{\text {nd }}$ edition. Thousand Oaks, CA: Sage.

Merkley, E., Bridgeman, A., Loewen, P.J., Owen, T., Ruths, D. \& Zhilin, O. 2020. “A rare moment of cross-partisan consensus: Elite and public response to the COVID-19 pandemic in Canada." Canadian Journal of Political Science, DOI: $\underline{\text { https://doi.org/10.1017/S0008423920000311 }}$ 
Migone, Andrea Riccardo. 2020. “Trust, but customize: federalism's impact on the Canadian COVID-19 response." Policy and Society, 39(3): 382-402.

Miller, A. 2020. Comparing the coronavirus curve. CBC News, April 2, 2020. https://newsinteractives.cbc.ca/coronaviruscurve

Mohammed, Anwar, Regan M. Johnston and Clifton van der Linden. 2020. "Public Responses to Policy Reversals: The Case of Mask Usage in Canada during COVID-19." Canadian Public Policy 46(S2): S119-S126.

Morey, B. N. 2018. "Mechanisms by which anti-immigrant stigma exacerbates racial/ethnic health disparities." American Journal of Public Health, 108(4): 460-463.

Morris, S., Fawcett, G., Brisebois, L., \& Hughes, J. 2018. “A demographic, employment and income profile of Canadians with disabilities aged 15 years and over, 2017.” Statistics Canada no. 89-654-X201800.

Olsson, Lennart, Anne Jerneck, Henrik Thoren, Johannes Persson and David O’Byrne. 2015 "Why resilience is unappealing to social science: Theoretical and empirical investigations of the scientific use of resilience." Science Advances 1(4): e1400217. 
Pennycook, Gordon, Jonathan McPhetres, Bence Bago and David G. Rand. 2020. "Predictors of attitudes and misperceptions about COVID-19 in Canada, the U.K., and the U.S.A." PsyArXiv July 2020. Doi: $\underline{10.31234 / 0 \text { sf.io/zhjkp. }}$

Pettinicchio, David. 2010. "Public and Elite Policy Preferences: Gay Marriage in Canada," International Journal of Canadian Studies 42(2):125-153.

Pettinicchio, David. 2017. “Elites, Policy, and Social Movements.” In Research in Political Sociology edited by Barbara Wejnert and Paolo Parigi, 155 - 190. Bingley, UK: Emerald Group Publishing Limited.

Pettinicchio, David. 2019. The Politics of Empowerment: Disability Rights and the Cycle of American Policy Reform. Stanford, CA: Stanford University Press

Pettinicchio, David and Michelle Maroto. 2020. "Combating Inequality: The Between- and Within-Group Effects of Unionization on Earnings for People with Different Disabilities.” The Sociological Quarterly, DOI: 10.1080/00380253.2020.1820918.

Pettinicchio, David and Michelle Maroto. 2021 forthcoming. "Who Counts? Measuring Disability Cross-Nationally in Census Data," Journal of Survey Statistics and Methodology, DOI: $10.1093 / \mathrm{jssam} / \mathrm{smaa} 046$ 
Prince, M. 2020. COVID-19, Canadians with disabilities, and the need for major reforms.

Broadbent Institute, June 23, 2020.

https://www.broadbentinstitute.ca/covid_19_canadians_with_disabilities_and_the_need_f or_major_reforms

Quinn, Sandra Crouse, John Parmer, Vicki S. Freimuth, Karen M. Hilyard, Donald Musa and Kevin H. Kim. 2013. "Exploring Communication, Trust in Government, and Vaccination Intention Later in the 2009 H1N1 Pandemic: Results of a National Survey." Biosecurity and Bioterrorism: Biodefense Strategy, Practice, and Science 11(2): 1-27.

Roser, M., H. Ritchie, E. Ortiz-Ospina \& J. Hasell. 2020. Coronavirus Pandemic (COVID-19). Published online at OurWorldInData.org. https://ourworldindata.org/coronavirus

Schonlau, Matthias, Arthur van Soest, Arie Kapteyn, and Mick Couper. 2009. "Selection Bias in Web Surveys and the Use of Propensity Scores." Sociological Methods \& Research 37(3):291-318.

Shakeri, S. 2020. Canadians with disabilities left out of federal coronavirus pandemic funding. Huffington Post, May 24, 2020. https://www.huffingtonpost.ca/entry/disabilitiescoronavirus-funding_ca_5ecaca68c5b680ec5006511c 
Shuey, Kim and Emily Jovic. 2013. "Disability Accommodation in Nonstandard and Precarious Employment Arrangements." Work and Occupations 40(2):174-205.

Snell, J. 2020. Winnipeg MP pushes to convert CERB to basic income for Canadians. Winnipeg Sun, August 12, 2020. https://winnipegsun.com/news/news-news/winnipeg-mp-pushes$\underline{\text { to-convert-cerb-to-basic-income-for-canadians }}$

Statistics Canada. 2017. Population and dwelling counts, for Canada, provinces and territories, 2016 and 2011 censuses (table). Population and Dwelling Count Highlight Tables. 2016 Census. Statistics Canada Catalogue no. 98-402-X2016001. Ottawa. Released February 8, 2017. https://www12.statcan.gc.ca/census-recensement/2016/dp-pd/hlt-fst/pd$\mathrm{pl} /$ Table.cfm?Lang $=$ Eng $\& \mathrm{~T}=101 \& \mathrm{~S}=50 \& \mathrm{O}=\mathrm{A}$

Taha, S. A., K. Matheson, and H. Anisman. 2013. "The 2009 H1N1 Influenza Pandemic: The Role of Threat, Coping, and Media Trust on Vaccination Intentions in Canada." Journal of Health Communication 18 (3): 278-290.

The Canadian Press. 2020a. Coronavirus: Here's a timeline of COVID-19 cases in Canada. Global News, March 3, 2020. https://globalnews.ca/news/6627505/coronavirus-covidcanada-timeline/ 
The Canadian Press. 2020b. What's happened in Canada since WHO declared COVID-19 a pandemic. CBC News, April 11, 2020. https://www.cbc.ca/news/politics/covid-19timeline-canada-who-pandemic-1.5529920

The Canadian Press. 2020c. COVID-19 highlights existing barriers for Canadians with communication disabilities. CTV News, May 7, 2020. https://www.ctvnews.ca/health/coronavirus/covid-19-highlights-existing-barriers-for$\underline{\text { canadians-with-communication-disabilities-1.4929736 }}$

Van Rooij, M., A. Lusardi, and R. Alessie. 2011. "Financial Literacy and Stock Market Participation." Journal of Financial Economics 101(2):449-472.

Vigo, D., Patten, S., Pajer, K., Krausz, M., Taylor, S., Rush, B., ... \& Yatham, L. N. 2020. "Mental Health of Communities during the COVID-19 Pandemic." The Canadian Journal of Psychiatry, 65(10): 681-687.

Wall, K. 2017. "Low Income among Persons with a Disability in Canada." Insights on Canadian Society. Statistics Canada Catalogue no. 75-006-X. Ottawa: Ministry of Industry.

Willms, J., \& H. Montgomery. 2020. Coronavirus Update: Senators tell Ottawa to consider a universal basic income for economic recovery. The Globe \& Mail, July 14, 2020. 
https://www.theglobeandmail.com/canada/article-coronavirus-update-senators-tellottawa-to-consider-a-universal-basic/

Wilson, N., Chambers, T., Kvalsvig, A., Mizdrak, A., Nghiem, N., Summers, J., \& Baker, M. 2020. NZ's "Team of 5 million" has achieved the lowest COVID-19 death rate in the OECD-but there are still gaps in our pandemic response. Public Health Expert. July 22, 2020. https://blogs.otago.ac.nz/pubhealthexpert/2020/07/22/nzs-team-of-5-million-hasachieved-the-lowest-covid-19-death-rate-in-the-oecd-but-there-are-still-gaps-in-ourpandemic-response

Wiseman, N. 2007. In search of Canadian political culture. Vancouver: UBC Press. 


\section{Table 1 Descriptive Results for Support for Government Response}

\begin{tabular}{|c|c|c|c|c|}
\hline & Mean & $\begin{array}{r}\text { Negative } \\
\text { (Score 0-4) }\end{array}$ & $\begin{array}{r}\text { Neutral } \\
\text { (Score 5-7) }\end{array}$ & $\begin{array}{r}\text { Positive } \\
\text { (Score 8-10) }\end{array}$ \\
\hline Overall & 6.84 & 13.24 & 42.06 & 44.69 \\
\hline \multicolumn{5}{|l|}{ Disability type } \\
\hline Physical disability & 7.15 & 9.16 & 41.22 & 49.62 \\
\hline Cognitive disability & 6.53 & 17.19 & 38.28 & 44.53 \\
\hline Emotional disability & 6.63 & 14.13 & 44.24 & 41.64 \\
\hline Vision disability & 6.98 & 14.17 & 37.50 & 48.33 \\
\hline Hearing disability & 6.70 & 18.52 & 33.33 & 48.15 \\
\hline Other disability & 6.72 & 15.26 & 39.91 & 44.84 \\
\hline \multicolumn{5}{|l|}{ Chronic health condition } \\
\hline Asthma & 6.85 & 12.05 & 44.18 & 43.78 \\
\hline Cancer & 7.05 & 11.90 & 33.33 & 54.76 \\
\hline Chronic kidney disease & 7.19 & 6.25 & 43.75 & 50.00 \\
\hline Chronic respiratory or lung disease & 6.78 & 12.96 & 48.15 & 38.89 \\
\hline Diabetes & 7.10 & 11.07 & 38.17 & 50.76 \\
\hline Hypertension & 7.07 & 12.22 & 38.91 & 48.87 \\
\hline Obesity & 6.95 & 12.88 & 37.42 & 49.69 \\
\hline Immunocompromised & 6.61 & 17.65 & 45.10 & 37.25 \\
\hline Heart disease & 7.04 & 12.50 & 39.29 & 48.21 \\
\hline \multicolumn{5}{|l|}{ Political party affiliation } \\
\hline Liberal Party & 7.86 & 3.16 & 34.74 & 62.11 \\
\hline Conservative Party & 5.56 & 29.73 & 44.59 & 25.68 \\
\hline New Democratic Party & 7.03 & 10.00 & 42.78 & 47.22 \\
\hline Other & 6.27 & 16.33 & 50.61 & 33.06 \\
\hline \multicolumn{5}{|l|}{ Region } \\
\hline Ontario & 6.79 & 12.78 & 42.86 & 44.36 \\
\hline Quebec & 6.97 & 11.30 & 44.78 & 43.91 \\
\hline $\mathrm{BC}$ & 7.12 & 8.96 & 45.52 & 45.52 \\
\hline Prairie provinces & 6.45 & 20.60 & 36.18 & 43.22 \\
\hline Atlantic provinces & 7.28 & 9.23 & 38.46 & 52.31 \\
\hline \multicolumn{5}{|l|}{ Applied for CERB } \\
\hline No & 6.80 & 13.90 & 41.94 & 44.17 \\
\hline Yes & 6.96 & 10.86 & 42.53 & 46.61 \\
\hline \multicolumn{5}{|l|}{ Worsening financial situation } \\
\hline No & 7.06 & 10.84 & 41.16 & 48.00 \\
\hline Yes & 6.17 & 20.63 & 44.84 & 34.52 \\
\hline
\end{tabular}

SOURCE: 2020 COVID-19 Response Survey of People with Disabilities and Health Conditions, N = 1027 adults

NOTES: Answers to questions: In general, how would you rate the federal government's response to COVID-19? 
Table 2 Results from Multinomial Logistic Regression Models Predicting Three Categories of Federal Response Views

\begin{tabular}{|c|c|c|c|c|c|c|}
\hline & \multicolumn{2}{|c|}{ Negative } & \multicolumn{2}{|c|}{ Neutral } & \multicolumn{2}{|c|}{ Positive } \\
\hline & AME & SE & AME & SE & AME & SE \\
\hline Physical disability & $-.069 * * *$ & $(.014)$ & .042 & $(.048)$ & .028 & $(.043)$ \\
\hline Cognitive disability & $.041^{* * *}$ & $(.008)$ & -.085 & $(.047)$ & .043 & $(.047)$ \\
\hline Emotional disability & -.036 & $(.027)$ & -.016 & $(.050)$ & .052 & $(.027)$ \\
\hline Vision disability & .028 & $(.024)$ & -.065 & $(.034)$ & .038 & $(.042)$ \\
\hline Hearing disability & .087 & $(.056)$ & -.046 & $(.047)$ & -.041 & $(.030)$ \\
\hline Other disability & $.061 * * *$ & $(.011)$ & -.009 & $(.016)$ & $-.053 * * *$ & $(.015)$ \\
\hline Asthma & -.015 & $(.010)$ & .002 & $(.021)$ & .013 & $(.030)$ \\
\hline Cancer & -.037 & $(.038)$ & -.037 & $(.030)$ & .074 & (.049) \\
\hline Chronic kidney disease & $-.088^{*}$ & $(.044)$ & .068 & $(.037)$ & .020 & $(.053)$ \\
\hline Chronic respiratory or lung disease & -.027 & $(.034)$ & .109 & $(.120)$ & -.081 & $(.139)$ \\
\hline Diabetes & $-.049 * *$ & $(.016)$ & -.007 & $(.040)$ & .057 & $(.051)$ \\
\hline Hypertension & -.008 & $(.057)$ & .025 & $(.032)$ & -.017 & $(.031)$ \\
\hline Obesity & .011 & $(.050)$ & -.064 & $(.041)$ & .053 & $(.044)$ \\
\hline Immunocompromised & .055 & $(.041)$ & -.004 & $(.055)$ & -.051 & $(.039)$ \\
\hline Heart disease & -.011 & $(.046)$ & .028 & $(.045)$ & -.017 & $(.021)$ \\
\hline Age & -.001 & $(.001)$ & $-.005 *$ & $(.003)$ & $.006^{*}$ & $(.002)$ \\
\hline \multicolumn{7}{|l|}{ Gender (Ref: Male) } \\
\hline Female & $-.061 * * *$ & $(.015)$ & .061 & $(.052)$ & .000 & $(.038)$ \\
\hline Other & -.029 & $(.134)$ & -.059 & $(.128)$ & .087 & $(.094)$ \\
\hline \multicolumn{7}{|l|}{ Marital status (Ref: Never married) } \\
\hline Cohabiting & .005 & $(.011)$ & .062 & $(.052)$ & -.068 & $(.052)$ \\
\hline Married & -.018 & $(.028)$ & .068 & $(.037)$ & -.050 & $(.034)$ \\
\hline Formerly married & .000 & $(.033)$ & .016 & $(.031)$ & -.015 & $(.060)$ \\
\hline Any children & -.012 & $(.011)$ & .001 & $(.062)$ & .011 & $(.054)$ \\
\hline Non-white & $-.057 * *$ & $(.021)$ & $.071^{*}$ & $(.036)$ & -.014 & $(.021)$ \\
\hline Bachelor's degree or higher & .013 & $(.010)$ & $-.085 * * *$ & $(.021)$ & $.071 * *$ & $(.022)$ \\
\hline \multicolumn{7}{|l|}{ Employment status (Ref: Employed, full-time) } \\
\hline Employed, part-time & .025 & $(.014)$ & -.016 & $(.061)$ & -.009 & $(.063)$ \\
\hline Unemployed & .105 & $(.056)$ & -.010 & $(.060)$ & -.094 & $(.071)$ \\
\hline Not in labor force & .000 & $(.016)$ & .061 & $(.036)$ & -.061 & $(.034)$ \\
\hline Own home & -.003 & $(.019)$ & -.010 & $(.017)$ & .013 & $(.013)$ \\
\hline Financial situation worse than previous year & $.038 * *$ & $(.014)$ & .038 & $(.020)$ & $-.076 * * *$ & $(.017)$ \\
\hline \multicolumn{7}{|l|}{ Political party (Ref: Liberal Party) } \\
\hline Conservative Party & $.260 * * *$ & $(.037)$ & .106 & $(.059)$ & $-.366^{* * *}$ & $(.041)$ \\
\hline New Democratic Party & $.059 * * *$ & $(.013)$ & .048 & $(.051)$ & -.106 & $(.061)$ \\
\hline Other & $.123 * * *$ & $(.024)$ & .118 & $(.069)$ & $-.242 * *$ & $(.075)$ \\
\hline \multicolumn{7}{|l|}{ Province/Region (Ref: Ontario) } \\
\hline Quebec & .011 & $(.010)$ & .001 & $(.016)$ & -.012 & $(.013)$ \\
\hline $\mathrm{BC}$ & $-.030 * * *$ & $(.007)$ & .012 & $(.008)$ & $.018 * *$ & $(.006)$ \\
\hline Prairie provinces & $.032 * * *$ & $(.008)$ & $-.087 * * *$ & $(.010)$ & $.055^{* * *}$ & $(.005)$ \\
\hline Atlantic provinces & $-.038 * * *$ & $(.007)$ & -.012 & $(.012)$ & $.051^{* *}$ & $(.017)$ \\
\hline COVID-19 expenses & .019 & $(.042)$ & -.056 & $(.096)$ & .037 & $(.069)$ \\
\hline Informed about COVID-19 & $-.040 * *$ & $(.012)$ & $-.121 * * *$ & $(.033)$ & $.161 * * *$ & $(.037)$ \\
\hline Concerned about COVID-19 & .007 & $(.022)$ & -.036 & $(.067)$ & .029 & $(.048)$ \\
\hline Applied for CERB & $-.054 *$ & $(.021)$ & -.027 & $(.047)$ & $.081 * *$ & $(.031)$ \\
\hline $\begin{array}{l}\text { Pseudo R-Squared } \\
* * \mathrm{p}<001, * * \mathrm{p}<01, * \mathrm{p}<0.05\end{array}$ & .141 & & .141 & & .141 & \\
\hline
\end{tabular}


This article has undergone peer review and been accepted for publication by the Canadian Public Policy/Analyse de politiques. Due to the importance of the subject matter, and the rapidly changing nature of the topic, the accepted version has been released. A final, copyedited and formatted version will be published at a later date.

SOURCE: 2020 COVID-19 Response Survey of People with Disabilities and Health Conditions, N = 1027 adults

NOTES: Multinomial logistic regression models predicting probability of negative, neutral, or positive perceptions of government COVID-19

response. Continuous variables are mean centered. AME refers to average marginal effects, which can be interpreted as a percentage point change in the probability of the outcome category associated with a unit change in the predictor variable. Standard errors are in parentheses. 


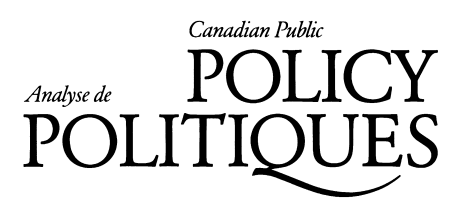

This article has undergone peer review and been accepted for publication by the Canadian Public Policy/Analyse de politiques. Due to the importance of the subject matter, and the rapidly changing nature of the topic, the accepted version has been released. A final, copyedited and formatted version will be published at a later date.

\section{Figure 1 Predicted Probabilities from Multinomial Logistic Regression Models Predicting Three Categories of Federal Response Views by Type of Disability and Chronic Health Condition}

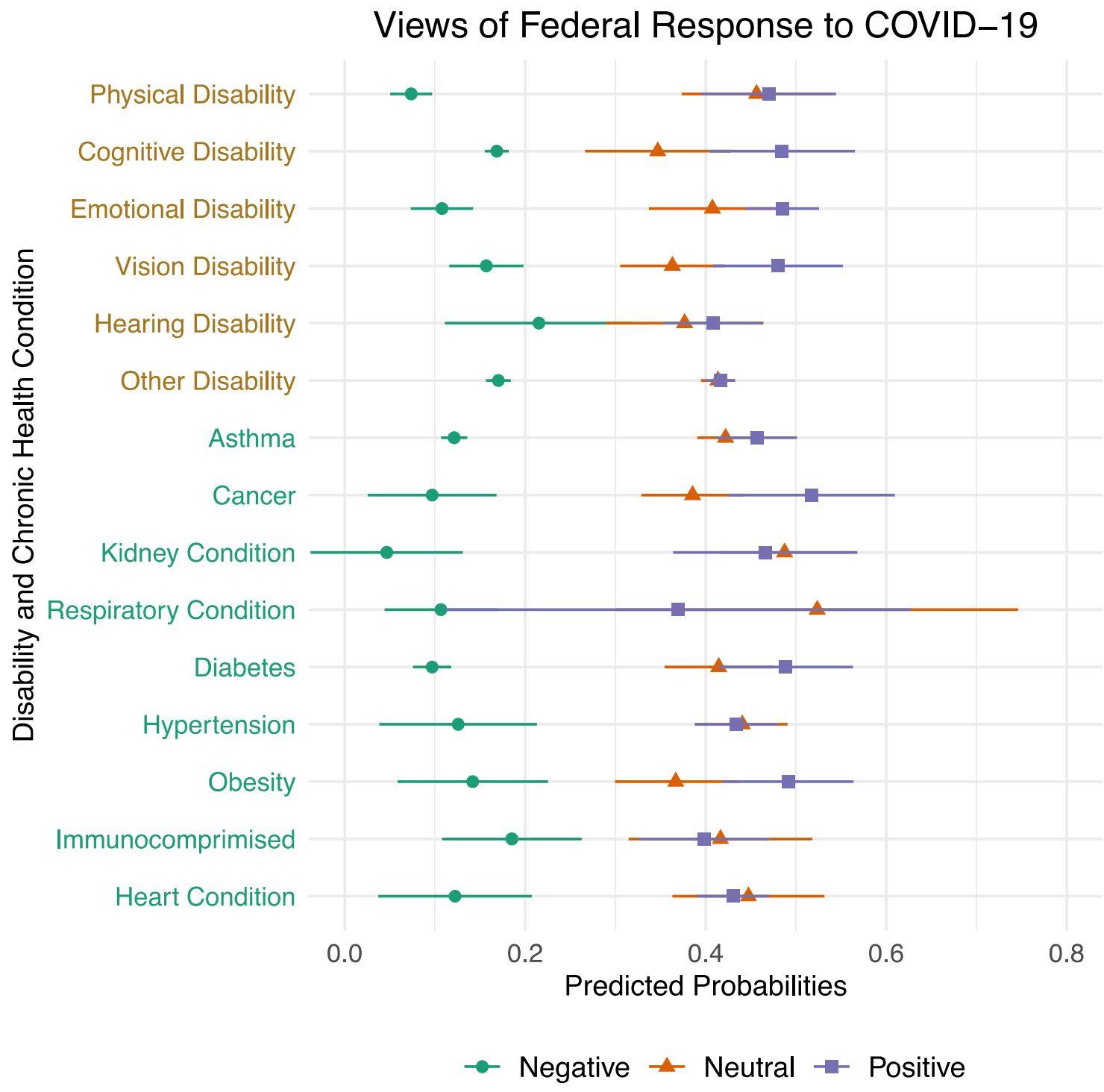

SOURCE: 2020 COVID-19 Response Survey of People with Disabilities and Health Conditions, $\mathrm{N}=1027$ adults

NOTES: Predicted probabilities based on models in Table 2. 


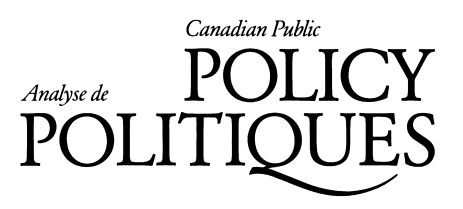

This article has undergone peer review and been accepted for publication by the Canadian Public Policy/Analyse de politiques. Due to the importance of the subject matter, and the rapidly changing nature of the topic, the accepted version has been released. A final, copyedited and formatted version will be published at a later date.

\section{Figure 2 Predicted Probabilities from Multinomial Logistic Regression Models Predicting Three Categories of Federal Response Views by Political Ideology and Region}

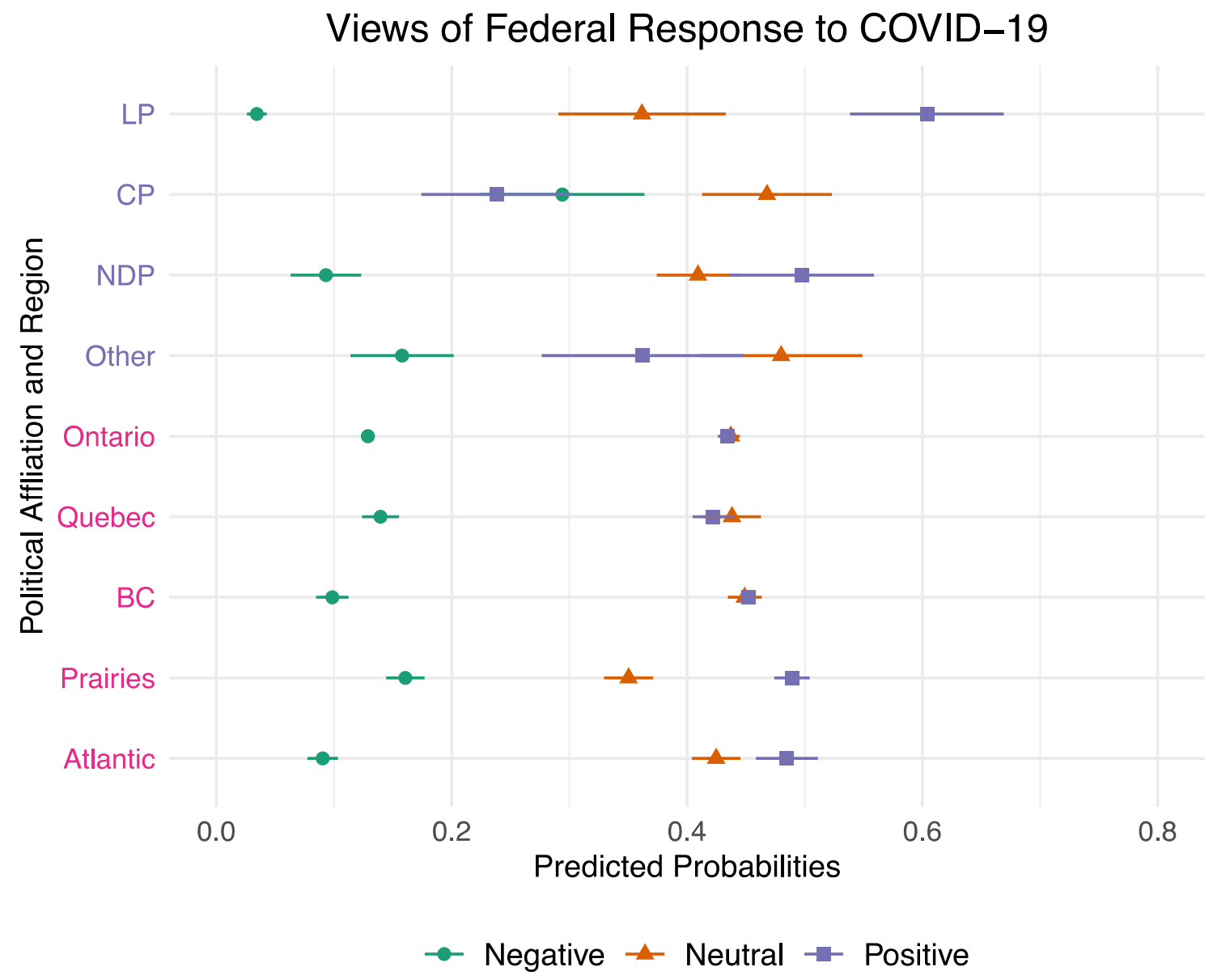

SOURCE: 2020 COVID-19 Response Survey of People with Disabilities and Health Conditions, $\mathrm{N}=1027$ adults

NOTES: Predicted probabilities based on models in Table 2. 

the importance of the subject matter, and the rapidly changing nature of the topic, the accepted version has been released. A final, copyedited and formatted version will be published at a later date.

Figure 3 Predicted Probabilities from Multinomial Logistic Regression Models Predicting Three Categories of Federal Response Views by COVID-19 Experiences

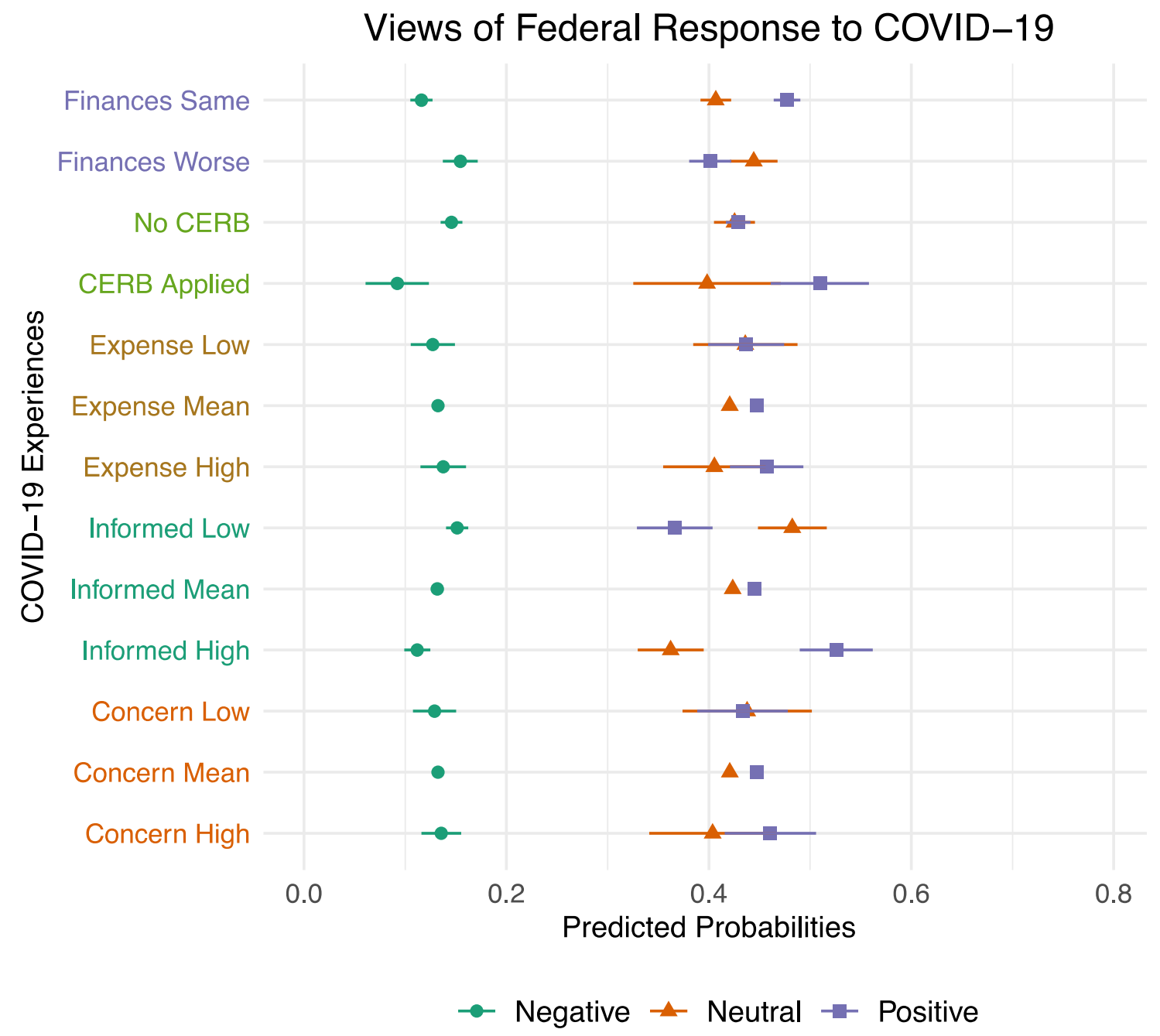

SOURCE: 2020 COVID-19 Response Survey of People with Disabilities and Health Conditions, $\mathrm{N}=1027$ adults

NOTES: Predicted probabilities based on models in Table 2. 


\section{Appendix A: Survey Data Information and Descriptive Overview}

The 2020 COVID-19 Response Survey of People with Disabilities and Health Conditions is a quota-based online survey administered from June 11-22, 2020 with the help of Qualtrics (https://www.qualtrics.com), an internet-based survey company, to obtain a sample of people with disabilities and health conditions across provinces. Qualtrics recruits participants from a range of online research panels with which the company partners. These panels consist of pools of people who have been recruited to take regular surveys for academic and corporate researchers. Panelists provide detailed and updated personal information to panel maintainers, including demographic information. Qualtrics, as a panel aggregator, matches respondents to surveys based on their profiles and randomly selects them to take surveys that they are likely to quality for, based on a given survey's eligibility criteria.

In the case of our online survey, we provided Qualtrics with eligibility criteria based on age, region, and health and disability status, which it used to recruit participants from appropriate online panels to our survey. Qualtrics takes steps to ensure that a respondent does not take the same survey multiples times or self-select into particular surveys based on the survey topic and incentives. Our survey instrument also included additional screening questions and attention checks to mitigate potential data quality issues. We included location-based sampling quotas to ensure that the proportion of respondents from each province within our final sample matches the proportion of the Canadian population located in each province. 
Online samples of the type used in this survey are common in the social sciences and frequently used as an alternative to much costlier traditional survey and sampling methods, such as those based on telephone interviews and random digit dialing.

We began with 1,392 respondents. Twenty-nine cases were initially dropped due to poor quality (including gibberish) in their qualitative responses. An additional 51 cases were removed as respondents did not complete the survey. In order to ensure that respondents were carefully reading and answering the survey questions, we included two quality control screening questions that required respondents provide a specific answer. Those who did not correctly answer both quality control questions were screened out of the survey. A final 285 cases were removed because respondents either did not meet the inclusion criteria or failed quality control and attention checks. This resulted in our final sample of 1,027 respondents with no missing data across variables.

The median survey response time was 20 minutes and the mean was 29 minutes. Survey response times ranged from 6 minutes to 15 hours. Longer response times likely reflected instances where respondents began the survey, left it open on their devices, and then went back to complete it later on. Ninety-five percent of respondents completed the survey in under one hour and $80 \%$ of respondents completed the survey in less than thirty minutes.

\section{Descriptive Information}

Table A1 presents descriptive statistics for our survey sample. The mean age for respondents in our sample was 49 years, which is older than the mean age of 41 years for the population in 2016 
(Statistics Canada 2020a). This was expected, however, because disabilities and chronic health conditions tend to be more prevalent among older population (CCDSS 2019; Morris et al. 2018).

\section{[Table A1]}

The gender make-up of our sample was 53\% female, $46 \%$ male, and $1 \%$ non-binary or other. According to the $2017 \mathrm{CSD}$, disabilities are more prevalent among women; 56\% of people with disabilities were female (Morris et al. 2018, p. 8). Ninety percent of respondents self-identified as heterosexual, 3.5\% identified as homosexual (gay or lesbian), $5.0 \%$ as bisexual, and $1.3 \%$ reported other identities, such as asexual, transgender, and two spirit. Data on sexual orientation are limited, but across several U.S. and Canadian studies $1-2.3 \%$ of the population identified as gay or lesbian, $0.7-2.9 \%$ as bisexual, and $0.6 \%$ as transgender (Waite and Denier 2019). A greater proportion of respondents identified as a sexual minority in our data than as estimated for the larger population. However, additional research shows that rates of disability tend to be higher among lesbian, gay, and bisexual adults (Fredricksen-Goldsen, Kim, and Barkan 2012).

In terms of education, $22.8 \%$ of respondents had a high school diploma or less education; $11.1 \%$ had some post-secondary education but no diploma; $31.1 \%$ completed an apprenticeship, trades, or college certificate; $24.7 \%$ had a Bachelor's degree; and $10.3 \%$ obtain a degree beyond a Bachelor's, such as a doctorate, master's, or professional degree. Respondents obtained somewhat more education than the population across Canada. Among adults age 25-64 in Canada, 35.3\% had a high school diploma or less (this includes people with some post-secondary education but no 
degree; $36.3 \%$ had an apprenticeship, trades, college certificate, or university certificate below a Bachelor's degree; and 28.5\% obtained a Bachelor's degree or higher in 2016 (Statistics Canada 2020b).

Approximately $35.2 \%$ of respondents were employed full-time and another $12.6 \%$ were employed part-time, $4.4 \%$ were unemployed, and $47.9 \%$ were not in the labor force, which included homemakers, students, retired persons, and people unable to work due to COVID-19. In this sample, $8.8 \%$ of respondents reported that they were unable to work due to COVID-19. According to the 2017 CSD the employment rate among people with disabilities was 59.4\% (Morris et al. 2018), which indicates a lower employment rate in our sample (47.8\%). However, percentages are much closer when respondents unable to work due to COVID-19 considered.

Racialized groups are likely underrepresented in this sample. The percentage who identify as Indigenous within our sample (2.3\%) was approximately half that of the percentage in the larger population (4.9\%) in 2016 (Statistics Canada 2020a). The percentage who identify as non-white in our sample (17.8\%) was also lower than the percentage of people who identify as visible minorities in Canada (22.3\%). Immigrants and non-citizens were also underrepresented in this sample with $14.4 \%$ of respondents indicating they immigrated to Canada compared to $21.9 \%$ of the population and $5.5 \%$ of respondents indicating that they were not Canadian citizens compared to $7.0 \%$ of the population. However, again, it is not clear as to whether these groups are over- or under-represented within groups of people with disabilities and CHCs. 
When comparing sample respondents to individuals age 15 and older in Canada, the sample closely mirrored the population in terms of marital status and household size. Within the sample, 53.0\% of respondents were married or cohabiting, $31.5 \%$ were never married, and $15.5 \%$ were formerly married. Across Canada in 2016, 57.4\% of individuals age 15 and older were married or in common law relationships, $28.2 \%$ were never married, and $14.2 \%$ were formerly married (Statistics Canada 2020a).

Finally, data were collected via quota-based sampling to ensure that we obtained a representative sample across provinces. We obtained a sample with $38 \%$ of responses from Ontario, $23 \%$ from Québec, 13\% from British Columbia, 18\% from the Prairie provinces (Alberta, Manitoba, Saskatchewan), and $7 \%$ from the Atlantic provinces (Newfoundland and Labrador, New Brunswick, Nova Scotia, and Prince Edward Island) based on 2016 Census population estimates.

\section{Disability and chronic health conditions}

Table A2 provides further information regarding the prevalence of different disabilities and chronic health conditions among sample participants. Overall, 10.6\% of respondents reported a single disability or condition, $35.0 \%$ reported $2-3$ disabilities or conditions, $32.4 \%$ reported $4-5$ disabilities or conditions, and $22.0 \%$ reported six or more disabilities or conditions.

Disability-related questions allowed respondents to indicate the severity of their disability by reporting whether they sometimes, often, or always experienced any vision, hearing, physical, 
cognitive, emotional, or other difficulties. Table A2 includes rates of any disability for whether the respondent indicated sometimes, often, or always and rates of more severe disabilities for whether the respondent indicated often or always. In both cases, emotional or other disabilities were the most commonly reported.

Regarding chronic health conditions, diabetes, asthma, hypertension, and obesity were the most common chronic health conditions reported by participants. Fewer participants $(<6 \%)$ reported conditions like cancer, kidney disease, respiratory disease, heart disease, and being immunocompromised.

\section{[Table A2]}




\section{Table A1 Descriptive Overview of Data}

\begin{tabular}{|c|c|c|c|c|}
\hline \multirow{4}{*}{ Age (mean years) } & \multirow{4}{*}{$\begin{array}{c}\text { Sample } \\
\text { Frequency }\end{array}$} & \multicolumn{3}{|c|}{ Proportion or Mean } \\
\hline & & \multirow{2}{*}{ Estimate } & \multicolumn{2}{|c|}{$95 \%$ Confidence Interval } \\
\hline & & & Lower & Upper \\
\hline & & 48.999 & 47.923 & 50.075 \\
\hline \multicolumn{5}{|l|}{ Gender } \\
\hline Male & 472 & 0.460 & 0.429 & 0.490 \\
\hline Female & 544 & 0.530 & 0.499 & 0.560 \\
\hline Non-binary or other & 11 & 0.011 & 0.004 & 0.017 \\
\hline \multicolumn{5}{|l|}{ Sexual identity } \\
\hline Heterosexual & 927 & 0.903 & 0.884 & 0.921 \\
\hline Homosexual & 36 & 0.035 & 0.024 & 0.046 \\
\hline Bisexual & 51 & 0.050 & 0.036 & 0.063 \\
\hline Other & 13 & 0.013 & 0.006 & 0.020 \\
\hline Member of a racialized minority group & 184 & 0.179 & 0.156 & 0.203 \\
\hline Immigrant & 148 & 0.144 & 0.123 & 0.166 \\
\hline Indigenous & 24 & 0.023 & 0.014 & 0.033 \\
\hline First language other than English or French & 50 & 0.049 & 0.036 & 0.062 \\
\hline \multicolumn{5}{|l|}{ Employment status (reduced variable) } \\
\hline Employed & 490 & 0.477 & 0.447 & 0.508 \\
\hline Unemployed & 45 & 0.044 & 0.031 & 0.056 \\
\hline NILF (homemaker, retired, in school) & 402 & 0.391 & 0.362 & 0.421 \\
\hline Unable to work due to COVID-19 & 90 & 0.088 & 0.070 & 0.105 \\
\hline \multicolumn{5}{|l|}{ Education } \\
\hline HS or less & 234 & 0.228 & 0.202 & 0.254 \\
\hline Some PSE, no degree & 114 & 0.111 & 0.092 & 0.130 \\
\hline $\begin{array}{l}\text { Apprenticeship, trades, or college } \\
\text { certificate }\end{array}$ & 319 & 0.311 & 0.282 & 0.339 \\
\hline Bachelor's degree & 254 & 0.247 & 0.221 & 0.274 \\
\hline Advanced degree & 106 & 0.103 & 0.085 & 0.122 \\
\hline \multicolumn{5}{|l|}{ Marital status } \\
\hline Never married & 324 & 0.315 & 0.287 & 0.344 \\
\hline Cohabiting & 138 & 0.134 & 0.114 & 0.155 \\
\hline Married & 406 & 0.395 & 0.365 & 0.425 \\
\hline Formerly married & 159 & 0.155 & 0.133 & 0.177 \\
\hline Any children & 246 & 0.240 & 0.213 & 0.266 \\
\hline \multicolumn{5}{|l|}{ Number of adults in household } \\
\hline Single adult (self) & 329 & 0.320 & 0.292 & 0.349 \\
\hline Two adults & 484 & 0.471 & 0.441 & 0.502 \\
\hline Three adults & 124 & 0.121 & 0.101 & 0.141 \\
\hline Four adults & 65 & 0.063 & 0.048 & 0.078 \\
\hline Five or more adults & 25 & 0.024 & 0.015 & 0.034 \\
\hline \multicolumn{5}{|l|}{ Province (reduced) } \\
\hline Ontario & 399 & 0.389 & 0.359 & 0.418 \\
\hline Quebec & 230 & 0.224 & 0.198 & 0.249 \\
\hline $\mathrm{BC}$ & 134 & 0.130 & 0.110 & 0.151 \\
\hline Prairie provinces & 199 & 0.194 & 0.170 & 0.218 \\
\hline Atlantic provinces & 65 & 0.063 & 0.048 & 0.078 \\
\hline
\end{tabular}

SOURCE: 2020 COVID-19 Response Survey of People with Disabilities and Health Conditions, N = 1027 adults NOTES: Estimates refer to sample data. Estimates provided as proportions unless otherwise specified. 
Table A2 Descriptive Statistics for Disability and Chronic Health Condition Variables

\begin{tabular}{|c|c|c|c|c|}
\hline & \multirow{3}{*}{$\begin{array}{l}\text { Sample } \\
\text { Frequency }\end{array}$} & \multicolumn{3}{|c|}{ Proportion or Mean } \\
\hline & & \multirow{2}{*}{ Estimate } & \multicolumn{2}{|c|}{$95 \%$ Confidence Interval } \\
\hline & & & Lower & Upper \\
\hline \multicolumn{5}{|l|}{$\begin{array}{l}\text { Number of disabilities or chronic health } \\
\text { conditions }\end{array}$} \\
\hline One & 109 & 0.106 & 0.087 & 0.125 \\
\hline Two or three & 359 & 0.350 & 0.320 & 0.379 \\
\hline Four or five & 333 & 0.324 & 0.296 & 0.353 \\
\hline Six or more & 226 & 0.220 & 0.195 & 0.245 \\
\hline \multicolumn{5}{|l|}{ Disability type (Any) } \\
\hline Vision & 558 & 0.543 & 0.513 & 0.574 \\
\hline Hearing & 270 & 0.263 & 0.236 & 0.290 \\
\hline Physical & 433 & 0.422 & 0.391 & 0.452 \\
\hline Cognitive & 502 & 0.489 & 0.458 & 0.519 \\
\hline Emotional & 565 & 0.550 & 0.520 & 0.581 \\
\hline Other & 591 & 0.575 & 0.545 & 0.606 \\
\hline \multicolumn{5}{|l|}{ Disability type (Always or Often) } \\
\hline Vision & 120 & 0.117 & 0.097 & 0.136 \\
\hline Hearing & 54 & 0.053 & 0.039 & 0.066 \\
\hline Physical & 131 & 0.128 & 0.107 & 0.148 \\
\hline Cognitive & 128 & 0.125 & 0.104 & 0.145 \\
\hline Emotional & 269 & 0.262 & 0.235 & 0.289 \\
\hline Other & 426 & 0.415 & 0.385 & 0.445 \\
\hline \multicolumn{5}{|l|}{ Chronic health condition } \\
\hline Asthma & 249 & 0.242 & 0.216 & 0.269 \\
\hline Cancer & 42 & 0.041 & 0.029 & 0.053 \\
\hline Chronic kidney disease & 16 & 0.016 & 0.008 & 0.023 \\
\hline Chronic respiratory or lung disease & 54 & 0.053 & 0.039 & 0.066 \\
\hline Diabetes & 262 & 0.255 & 0.228 & 0.282 \\
\hline Hypertension & 221 & 0.215 & 0.190 & 0.240 \\
\hline Obesity & 163 & 0.159 & 0.136 & 0.181 \\
\hline Immunocompromised & 51 & 0.050 & 0.036 & 0.063 \\
\hline Heart disease & 56 & 0.055 & 0.041 & 0.068 \\
\hline
\end{tabular}

SOURCE: 2020 COVID-19 Response Survey of People with Disabilities and Health Conditions, N = 1027 adults

NOTES: Estimates refer to sample data. Estimates provided as proportions unless otherwise specified. 


\section{Appendix B: Comparison with CCHS Data}

To further verify the representativeness of our sample, we compare our data to a subsample of the 2017-18 Canadian Community Health Survey (CCHS). Although this survey does not include identical disability and health condition variables, it does provide variables close enough to ours to allow for a comparison of demographics across a subsample of adults age $18+$ with reported disabilities or chronic health conditions.

The original 2017-18 CCHS sample included 113,290 cases. Removing missing data for our variables of interest and restricting the sample to adults age 18 and older living in provinces reduced our sample size to 94,797 cases. We then restricted this sample to individuals who reported one or more disabilities or chronic health conditions, which resulted in a final sample size of 60,082 cases.

Within this sample, a respondent is considered as having a disability if they indicated that they had some difficulty, a lot of difficulty, or inability (cannot do at all) in regard to seeing (even with glasses), hearing (even with a hearing aid), walking or climbing stairs, remembering or concentrating, self-care, or communicating. In order to include emotional disabilities, we also counted individuals who reported that they had a major mood or anxiety disorder.

We also included individuals with the following chronic health conditions: asthma, respiratory conditions, hypertension, heart diseases, diabetes, and cancer. Although we also wanted to include 
obesity in this analysis, we omitted this variable due to the amount of missing data with it. The survey also did not include questions regarding being immunocompromised.

Table B1 presents information regarding the prevalence of disability and chronic health conditions in the full CCHS sample. In the larger sample, $43.7 \%$ of respondents reported any disability (having at least some difficulty across designated areas) and $18.1 \%$ reported a more severe disability (having a lot of difficulty or cannot do at all). Additional, 30.9\% of respondents reported having one of six designated chronic health conditions.

\section{[Table B1]}

Table B2 presents descriptive statistics for demographic variables in the CCHS subset of people with disabilities or chronic health conditions. Comparing these to data from the 2020 COVID-19

Disability Survey, the CCHS sample is slightly older with a mean age of 51.6 years compared to 49.0 years in the COVID-19 Disability Survey. Gender composition is similar across surveys with a slightly greater proportion of men in both. Notably, the CCHS did not permit respondents to report a gender other than male or female. We also do not include a comparison based on sexual identity due to the larger percentage of missing data on this variable in the CCHS.

Similar to earlier comparisons with national population data, a comparison with the CCHS again shows that immigrants and Indigenous persons were underrepresented within the COVID-19 Disability Survey sample. It also shows that our sample has attained somewhat higher levels of 
education with $66.1 \%$ of the COVID-19 Disability Survey obtaining a PSE certificate or higher compared to $59.1 \%$ of CCHS respondents. Employment rates were closer across surveys. In the COVID-19 Disability Survey, $47.7 \%$ of respondents were employed at the time of the survey compared to $50.0 \%$ of CCHS respondents. As expected during the pandemic, the unemployment rate among COVID-19 Disability Survey respondents was higher.

The CCHS marital status variable categories differ from those used in the COVID-19 Disability Survey, but it appears as those marriage rates were lower in the COVID-19 Disability Survey. Within the COVID-19 Disability Survey $39.5 \%$ of respondents were married, $13.4 \%$ were cohabiting, $15.5 \%$ were formerly married, and $31.5 \%$ were never married. Within the CCHS, $50.0 \%$ of respondents were married, $11.8 \%$ were in common law unions, $16.1 \%$ were formerly married, and $22.1 \%$ were single.

\section{[Table B2]}

Finally, Table B3 presents information regarding the prevalence of different types of disabilities and chronic health conditions in the CCHS subsample. This table shows that most specific disabilities were more prevalent across respondents in the COVID-19 Disability Survey. A greater percentage of COVID-19 Disability Survey respondents were also more likely to report most conditions, except for hypertension and heart disease, which were more prevalent in the CCHS subsample. 
It is important to note that the ways in which questions were phrased and the options given to respondents differ across surveys. For instance, COVID-19 Disability Survey respondents were given options of "no," "sometimes," "always," and "never." CCHS respondents were given options of "no difficulty," "some difficulty," "a lot of difficulty," and "cannot do at all / unable to do."

\section{[Table B3]}

Overall, this comparison between the 2020 COVID-19 Disability Survey and the 2017-18 CCHS subsample of people with disabilities and chronic health conditions shows both similarities and differences across survey respondents. Although age and gender composition are similar across survey respondents, differences do appear in regard to race and education. It is important to note that the disabilities and conditions included across surveys are not identical, however, a factor that could also affect the composition of survey respondents. 
Table B1 Descriptive Statistics for Full Sample, 2017-18 CCHS

\begin{tabular}{lrrrrr}
\hline & \multirow{2}{*}{$\begin{array}{c}\text { Sample } \\
\text { Frequency }\end{array}$} & Estimate & & \multicolumn{3}{c}{$95 \%$ Confidence Interval } \\
\cline { 3 - 6 } & & & & Lower & \multicolumn{2}{c}{ Upper } \\
\hline Disability (Any) & 47223 & 0.437 & 0.432 & 0.443 \\
Disability (More severe) & 19941 & 0.181 & 0.177 & 0.185 \\
Health condition & 35458 & 0.309 & 0.304 & 0.314
\end{tabular}

SOURCE: $2017-18$ CCHS, $\mathrm{N}=94,794$ adults age $18+$ living in provinces

NOTES: Estimates include survey provided sample weights 
Table B2 Descriptives Statistics for Demographic Variables, 2017-18 CCHS Subsample

\begin{tabular}{|c|c|c|c|c|}
\hline & \multirow{3}{*}{$\begin{array}{l}\text { Sample } \\
\text { Frequency }\end{array}$} & \multicolumn{3}{|c|}{ Proportion or Mean } \\
\hline & & \multirow{2}{*}{ Estimate } & \multicolumn{2}{|c|}{$95 \%$ Confidence Interval } \\
\hline & & & Lower $\quad \mathrm{L}$ & \\
\hline Age (mean years) & -- & 51.601 & 51.341 & 51.861 \\
\hline \multicolumn{5}{|l|}{ Gender } \\
\hline Male & 26988 & 0.480 & 0.472 & 0.487 \\
\hline Female & 33094 & 0.520 & 0.513 & 0.528 \\
\hline Immigrant & 9056 & 0.241 & 0.234 & 0.248 \\
\hline Indigenous & 3164 & 0.042 & 0.040 & 0.045 \\
\hline \multicolumn{5}{|l|}{ Main activity } \\
\hline Paid work & 24377 & 0.500 & 0.493 & 0.507 \\
\hline Unemployed & 1570 & 0.028 & 0.026 & 0.030 \\
\hline NILF & 34135 & 0.472 & 0.465 & 0.479 \\
\hline \multicolumn{5}{|l|}{ Education } \\
\hline Less than HS & 11462 & 0.151 & 0.146 & 0.155 \\
\hline HS graduate & 15002 & 0.258 & 0.252 & 0.265 \\
\hline Post-secondary education degree or higher & 33618 & 0.591 & 0.584 & 0.598 \\
\hline \multicolumn{5}{|l|}{ Marital status } \\
\hline Married & 25942 & 0.500 & 0.493 & 0.507 \\
\hline Common law & 5660 & 0.118 & 0.114 & 0.123 \\
\hline Formerly married & 16134 & 0.161 & 0.156 & 0.165 \\
\hline Single & 12346 & 0.221 & 0.215 & 0.227 \\
\hline \multicolumn{5}{|l|}{ Household size } \\
\hline Single person (self) & 21015 & 0.187 & 0.182 & 0.191 \\
\hline Two people & 24636 & 0.397 & 0.390 & 0.403 \\
\hline Three people & 6698 & 0.173 & 0.167 & 0.178 \\
\hline Four people & 5022 & 0.148 & 0.142 & 0.154 \\
\hline Five or more people & 2711 & 0.096 & 0.091 & 0.102 \\
\hline \multicolumn{5}{|l|}{ Living situation } \\
\hline Unattached individual living alone & 21015 & 0.187 & 0.182 & 0.191 \\
\hline Unattached individual living with others & 1810 & 0.044 & 0.041 & 0.047 \\
\hline Individual living with spouse/partner & 20602 & 0.323 & 0.317 & 0.329 \\
\hline Parent living with spouse/partner and child(ren) & 8590 & 0.229 & 0.223 & 0.236 \\
\hline Single parent living with children & 3184 & 0.051 & 0.048 & 0.054 \\
\hline Child living with a single parent with or without siblings & 1034 & 0.028 & 0.025 & 0.031 \\
\hline Child living with two parents with or without siblings & 1617 & 0.056 & 0.052 & 0.060 \\
\hline Other & 2230 & 0.082 & 0.077 & 0.088 \\
\hline \multicolumn{5}{|l|}{ Province (reduced) } \\
\hline Ontario & 18208 & 0.383 & 0.375 & 0.390 \\
\hline Quebec & 12643 & 0.226 & 0.220 & 0.231 \\
\hline $\mathrm{BC}$ & 8208 & 0.134 & 0.129 & 0.138 \\
\hline Prairie provinces & 12953 & 0.183 & 0.178 & 0.188 \\
\hline Atlantic provinces & 8070 & 0.075 & 0.072 & 0.078 \\
\hline
\end{tabular}


Table B3 Descriptive Statistics for Disability and Chronic Health Condition Variables, 2017-18 CCHS Subsample

\begin{tabular}{|c|c|c|c|c|}
\hline & \multirow{3}{*}{$\begin{array}{l}\text { Sample } \\
\text { Frequency }\end{array}$} & \multicolumn{3}{|c|}{ Proportion or Mean } \\
\hline & & \multirow{2}{*}{ Estimate } & \multicolumn{2}{|c|}{$\begin{array}{c}95 \% \text { Confidence } \\
\text { Interval } \\
\end{array}$} \\
\hline & & & Lower & Upper \\
\hline \multicolumn{5}{|l|}{ Disability type (Any) } \\
\hline Vision & 14723 & 0.243 & 0.237 & 0.249 \\
\hline Hearing & 14642 & 0.214 & 0.208 & 0.219 \\
\hline Physical & 18292 & 0.253 & 0.247 & 0.259 \\
\hline Cognitive & 18585 & 0.308 & 0.302 & 0.315 \\
\hline Self-care & 3677 & 0.054 & 0.051 & 0.057 \\
\hline Communication & 4210 & 0.072 & 0.068 & 0.075 \\
\hline Emotional & 13957 & 0.236 & 0.230 & 0.243 \\
\hline \multicolumn{5}{|l|}{ Disability type (More severe) } \\
\hline Vision & 1247 & 0.018 & 0.016 & 0.020 \\
\hline Hearing & 1760 & 0.024 & 0.022 & 0.026 \\
\hline Physical & 5327 & 0.067 & 0.064 & 0.070 \\
\hline Cognitive & 2062 & 0.035 & 0.033 & 0.038 \\
\hline Self-care & 793 & 0.012 & 0.010 & 0.013 \\
\hline Communication & 459 & 0.008 & 0.006 & 0.009 \\
\hline \multicolumn{5}{|l|}{ Chronic health condition } \\
\hline Asthma & 7975 & 0.140 & 0.135 & 0.144 \\
\hline Cancer & 2097 & 0.029 & 0.027 & 0.032 \\
\hline Chronic respiratory or lung disease & 4297 & 0.050 & 0.048 & 0.053 \\
\hline Diabetes & 8968 & 0.133 & 0.128 & 0.137 \\
\hline Hypertension & 22108 & 0.325 & 0.319 & 0.332 \\
\hline Heart disease & 6390 & 0.084 & 0.080 & 0.087 \\
\hline
\end{tabular}

SOURCE: $2017-18$ CCHS, $\mathrm{N}=60,082$ adults age $18+$ with reported disabilities or chronic health conditions living in provinces NOTES: Estimates include survey-provided sample weights Estimates provided as proportions unless otherwise specified. 


\section{Appendix C: Results from Models Predicting Support for Federal Government's COVID-}

\section{Response}

Table C1 presents results from multinomial logistic regression models predicting negative, neutral, or positive views of the federal government's COVID-19 response. The table shows model coefficients (b) and odds ratios (OR) for three comparisons. Model 1 compares neutral to negative responses. Model 2 compares positive to negative responses. Model 3 compares positive to neutral responses. These tables inform Table 2 and the figures in the full paper.

Tables C2-C4 present results from supplemental models assessing support for the federal government's COVID-19 response. Table C2 presents results from a linear regression model predicting support as a continuous variable ranging from 0 to 10 . Table $\mathrm{C} 3$ presents results from a logistic regression model predicting positive views of the government's response. Table C4 presents results from an ordinal logistic regression model predicting negative, neutral, or positive views of the federal government's COVID-19 response. 
Table C1. Results from Multinomial Logit Models Predicting Support for Federal Government's COVID-19 Response

\begin{tabular}{|c|c|c|c|c|c|c|c|c|c|}
\hline & \multicolumn{3}{|c|}{ (1.) Neutral vs. Negative } & \multicolumn{3}{|c|}{ (2.) Positive vs. Negative } & \multicolumn{3}{|c|}{ (3.) Positive vs. Neutral } \\
\hline & OR & $\mathbf{b}$ & SE & OR & $\mathbf{b}$ & SE & OR & $\mathbf{b}$ & SE \\
\hline Intercept & & $2.082 * * *$ & $(.241)$ & & $2.768 * * *$ & $(.195)$ & & $.686^{*}$ & $(.302)$ \\
\hline Physical disability & 2.368 & $.862 * * *$ & $(.261)$ & 2.363 & $.860 * * *$ & $(.224)$ & .998 & -.002 & $(.228)$ \\
\hline Cognitive disability & .580 & $-.544 * * *$ & $(.145)$ & .811 & -.209 & $(.155)$ & 1.397 & .334 & $(.266)$ \\
\hline Emotional disability & 1.364 & .311 & $(.377)$ & 1.657 & $.505^{*}$ & $(.216)$ & 1.215 & .195 & $(.193)$ \\
\hline Vision disability & .678 & -.389 & $(.199)$ & .886 & -.121 & $(.277)$ & 1.307 & .267 & $(.198)$ \\
\hline Hearing disability & .471 & -.754 & $(.455)$ & .457 & -.783 & $(.416)$ & .971 & -.029 & $(.153)$ \\
\hline Other disability & .569 & $-.564 * * *$ & $(.107)$ & .491 & $-.712 * * *$ & $(.103)$ & .862 & $-.148^{*}$ & $(.072)$ \\
\hline Asthma & 1.151 & $.140 *$ & $(.059)$ & 1.192 & .176 & $(.182)$ & 1.036 & .036 & $(.138)$ \\
\hline Cancer & 1.355 & .304 & $(.461)$ & 1.836 & .607 & $(.573)$ & 1.355 & .304 & $(.193)$ \\
\hline Chronic kidney disease & 3.819 & 1.340 & $(1.016)$ & 3.543 & 1.265 & $(1.133)$ & .928 & -.075 & $(.214)$ \\
\hline Chronic respiratory or lung disease & 1.620 & .483 & $(.339)$ & 1.000 & .000 & $(.801)$ & .617 & -.483 & $(.699)$ \\
\hline Diabetes & 1.609 & $.476^{* *}$ & $(.150)$ & 1.946 & $.666^{*}$ & $(.313)$ & 1.209 & .190 & $(.238)$ \\
\hline Hypertension & 1.141 & .132 & $(.597)$ & 1.026 & .025 & $(.626)$ & .899 & -.107 & $(.074)$ \\
\hline Obesity & .782 & -.246 & $(.500)$ & 1.066 & .064 & $(.526)$ & 1.363 & .310 & $(.188)$ \\
\hline Immunocompromised & .638 & -.450 & $(.382)$ & .545 & -.606 & $(.322)$ & .855 & -.157 & $(.231)$ \\
\hline Heart disease & 1.173 & .160 & $(.529)$ & 1.046 & .045 & $(.468)$ & .891 & -.115 & $(.127)$ \\
\hline Age & .997 & -.003 & $(.012)$ & 1.027 & $.027^{*}$ & $(.012)$ & 1.030 & $.030 *$ & $(.013)$ \\
\hline \multicolumn{10}{|l|}{ Gender (Ref: Male) } \\
\hline Female & 1.979 & $.683 * *$ & $(.244)$ & 1.738 & $.553 * * *$ & $(.054)$ & .878 & -.130 & $(.232)$ \\
\hline Other & 1.082 & .079 & $(1.454)$ & 1.629 & .488 & $(1.298)$ & 1.505 & .409 & $(.505)$ \\
\hline \multicolumn{10}{|l|}{ Marital status (Ref: Never married) } \\
\hline Cohabiting & 1.097 & .092 & $(.147)$ & .770 & -.262 & $(.212)$ & .702 & -.354 & $(.274)$ \\
\hline Married & 1.379 & .322 & $(.308)$ & 1.015 & .015 & $(.311)$ & .736 & -.307 & $(.176)$ \\
\hline Formerly married & 1.042 & .041 & $(.238)$ & .958 & -.043 & $(.467)$ & .919 & -.084 & $(.253)$ \\
\hline Any children & 1.123 & .116 & $(.228)$ & 1.160 & .148 & $(.121)$ & 1.033 & .032 & $(.304)$ \\
\hline Non-white & 2.094 & $.739 *$ & $(.323)$ & 1.737 & $.552 *$ & $(.242)$ & .830 & -.187 & $(.124)$ \\
\hline Bachelor's degree or higher & .732 & $-.312 * *$ & $(.100)$ & 1.103 & .098 & $(.130)$ & 1.507 & $.410 * * *$ & $(.114)$ \\
\hline \multicolumn{10}{|l|}{$\begin{array}{l}\text { Employment status (Ref: Employed, } \\
\text { full-time) }\end{array}$} \\
\hline Employed, part-time & .769 & -.263 & $(.192)$ & .776 & -.253 & $(.241)$ & 1.010 & .010 & $(.336)$ \\
\hline Unemployed & .455 & $-.788^{*}$ & $(.364)$ & .344 & $-1.066^{*}$ & $(.486)$ & .757 & -.278 & $(.364)$ \\
\hline Not in labor force & 1.140 & .131 & $(.200)$ & .828 & -.189 & $(.199)$ & .726 & -.320 & $(.178)$ \\
\hline Own home & 1.005 & .005 & $(.199)$ & 1.069 & .066 & $(.193)$ & 1.063 & .061 & $(.064)$ \\
\hline $\begin{array}{l}\text { Financial situation worse than } \\
\text { previous year }\end{array}$ & .770 & -.261 & $(.154)$ & .559 & $-.582 * * *$ & $(.158)$ & .726 & $-.320 * * *$ & $(.087)$ \\
\hline \multicolumn{10}{|l|}{ Political party (Ref: Liberal Party) } \\
\hline Conservative Party & .131 & $2.030^{* * *}$ & $(.327)$ & .035 & $-3.364 * * *$ & $(.257)$ & .263 & $-1.334 * * *$ & $(.236)$ \\
\hline New Democratic Party & .403 & $\begin{array}{l}-.908 * * * \\
-\end{array}$ & $(.145)$ & .281 & $-1.269 * * *$ & $(.233)$ & .697 & -.361 & $(.268)$ \\
\hline Other & .270 & $1.310^{* * *}$ & $(.323)$ & .110 & $-2.203 * * *$ & $(.321)$ & .409 & $-.893 *$ & $(.353)$ \\
\hline \multicolumn{10}{|l|}{ Province/Region (Ref: Ontario) } \\
\hline Quebec & .911 & -.093 & $(.108)$ & .875 & -.134 & $(.094)$ & .960 & -.041 & $(.072)$ \\
\hline $\mathrm{BC}$ & 1.400 & $.337 * * *$ & $(.086)$ & 1.449 & $.371 * * *$ & $(.079)$ & 1.035 & .035 & $(.029)$ \\
\hline
\end{tabular}


This article has undergone peer review and been accepted for publication by the Canadian Public Policy/Analyse de politiques. Due to the importance of the subject matter, and the rapidly changing nature of the topic, the accepted version has been released. A final, copyedited and formatted version will be published at a later date.

\begin{tabular}{lrllllllll}
\multicolumn{1}{c}{ Prairie provinces } & .626 & $-.468^{* * *}$ & $(.087)$ & .909 & -.096 & $(.060)$ & 1.451 & $.372 * * *$ & $(.038)$ \\
$\quad$ Atlantic provinces & 1.470 & $.385^{* * *}$ & $(.079)$ & 1.766 & $.569 * * *$ & $(.128)$ & 1.202 & $.184^{*}$ & $(.074)$ \\
COVID-19 expenses & .744 & -.296 & $(.559)$ & .945 & -.057 & $(.342)$ & 1.270 & .239 & $(.417)$ \\
Informed about COVID-19 & 1.107 & .102 & $(.125)$ & 2.385 & $.869 * * *$ & $(.190)$ & 2.154 & $.767 * * *$ & $(.179)$ \\
Concerned about COVID-19 & .869 & -.140 & $(.340)$ & 1.027 & .027 & $(.105)$ & 1.182 & .167 & $(.297)$ \\
Applied for CERB & 1.621 & .483 & $(.348)$ & 2.201 & $.789 * * *$ & $(.211)$ & 1.358 & .306 & $(.193)$ \\
Pseudo R-Squared & .141 & & & .141 & & & .141 & &
\end{tabular}
$* * * \mathrm{p}<.001, * * \mathrm{p}<.01, * \mathrm{p}<.05$ SOURCE: 2020 COVID-19 Response Survey of People with Disabilities and Health Conditions, N = 1027 adults

NOTES: Multinomial logistic regression models predicting probability of negative, neutral, or positive perceptions of government COVID-19 response. Continuous variables are mean centered. " $\mathrm{b}$ " refers to multinomial logit model coefficients. Odds ratios can be obtained by exponentiating (b). Standard errors are in parentheses. Standard errors account for clustering by province/region. 
Table C2. Results from Linear Regression Models Predicting Support for Federal Government's COVID-19 Response

\begin{tabular}{|c|c|c|}
\hline & \multicolumn{2}{|c|}{ Model 1} \\
\hline & $\mathbf{b}$ & SE \\
\hline Intercept & $7.621 * * *$ & $(.189)$ \\
\hline Physical disability & .455 & $(.245)$ \\
\hline Cognitive disability & -.176 & $(.155)$ \\
\hline Emotional disability & $.269 * * *$ & $(.070)$ \\
\hline Vision disability & .100 & $(.180)$ \\
\hline Hearing disability & -.433 & $(.306)$ \\
\hline Other disability & $-.498 * * *$ & $(.104)$ \\
\hline Asthma & .069 & $(.130)$ \\
\hline Cancer & .250 & $(.443)$ \\
\hline Chronic kidney disease & .446 & $(.573)$ \\
\hline Chronic respiratory or lung disease & -.022 & $(.677)$ \\
\hline Diabetes & .334 & $(.338)$ \\
\hline Hypertension & .106 & $(.251)$ \\
\hline Obesity & .042 & $(.214)$ \\
\hline Immunocompromised & -.192 & $(.212)$ \\
\hline Heart disease & .055 & $(.405)$ \\
\hline Age & $.023 * *$ & $(.008)$ \\
\hline \multicolumn{3}{|l|}{ Gender (Ref: Male) } \\
\hline Female & $.421 * * *$ & $(.082)$ \\
\hline Other & .074 & $(1.005)$ \\
\hline \multicolumn{3}{|l|}{ Marital status (Ref: Never married) } \\
\hline Cohabiting & $-.279 * * *$ & $(.067)$ \\
\hline Married & .000 & $(.125)$ \\
\hline Formerly married & -.009 & $(.265)$ \\
\hline Any children & -.003 & $(.099)$ \\
\hline Non-white & $.132 *$ & $(.053)$ \\
\hline Bachelor's degree or higher & .162 & $(.095)$ \\
\hline \multicolumn{3}{|l|}{ Employment status (Ref: Employed, full-time) } \\
\hline Employed, part-time & $-.311 * * *$ & $(.067)$ \\
\hline Unemployed & -.590 & $(.505)$ \\
\hline Not in labor force & -.229 & $(.155)$ \\
\hline Own home & .057 & $(.038)$ \\
\hline Financial situation worse than previous year & $-.444 * * *$ & $(.052)$ \\
\hline \multicolumn{3}{|l|}{ Political party (Ref: Liberal Party) } \\
\hline Conservative Party & $-2.261 * * *$ & $(.098)$ \\
\hline New Democratic Party & $-.613^{*}$ & $(.282)$ \\
\hline Other & $-1.364 * * *$ & $(.284)$ \\
\hline \multicolumn{3}{|l|}{ Province/Region (Ref: Ontario) } \\
\hline Quebec & .038 & $(.031)$ \\
\hline $\mathrm{BC}$ & $.315^{* * *}$ & $(.067)$ \\
\hline Prairie provinces & .001 & $(.017)$ \\
\hline Atlantic provinces & $.386 * * *$ & $(.094)$ \\
\hline COVID-19 expenses & .130 & $(.259)$ \\
\hline Informed about COVID-19 & $.633^{* * *}$ & $(.105)$ \\
\hline
\end{tabular}


POLITIQUES

This article has undergone peer review and been accepted for publication by the Canadian Public Policy/Analyse de politiques. Due to the importance of the subject matter, and the rapidly changing nature of the topic, the accepted version has been released. A final, copyedited and formatted version will be published at a later date.
Concerned about COVID-19

Applied for CERB

R-Squared

$* * * \mathrm{p}<.001, * * \mathrm{p}<.01, * \mathrm{p}<.05$

SOURCE: 2020 COVID-19 Response Survey of People with Disabilities and Health Conditions, N = 1027 adults

NOTES: Linear regression models predicting perceptions of government COVID-19 response on a scale of 0 to 10. Continuous variables are mean centered. "b" refers to model coefficients. Standard errors are in parentheses. Standard errors account for clustering by province/region. 
Table C3. Results from Logistic Regression Models Predicting Support for Federal Government's COVID-19 Response

\begin{tabular}{|c|c|c|c|}
\hline & \multicolumn{3}{|c|}{ Model 1} \\
\hline & OR & $\mathbf{b}$ & SE \\
\hline Intercept & & .518 & $(.277)$ \\
\hline Physical disability & 1.175 & .161 & $(.208)$ \\
\hline Cognitive disability & 1.244 & .218 & $(.244)$ \\
\hline Emotional disability & 1.284 & .250 & $(.142)$ \\
\hline Vision disability & 1.216 & .195 & $(.204)$ \\
\hline Hearing disability & .806 & -.216 & $(.161)$ \\
\hline Other disability & .774 & $-.256 * * *$ & $(.074)$ \\
\hline Asthma & 1.061 & .059 & $(.152)$ \\
\hline Cancer & 1.432 & .359 & $(.252)$ \\
\hline Chronic kidney disease & 1.171 & .158 & $(.255)$ \\
\hline Chronic respiratory or lung disease & .681 & -.384 & $(.739)$ \\
\hline Diabetes & 1.315 & .274 & $(.265)$ \\
\hline Hypertension & .926 & -.076 & $(.162)$ \\
\hline Obesity & 1.302 & .264 & $(.195)$ \\
\hline Immunocompromised & .786 & -.241 & $(.197)$ \\
\hline Heart disease & .907 & -.098 & $(.118)$ \\
\hline Age & 1.030 & $.029 *$ & $(.012)$ \\
\hline \multicolumn{4}{|l|}{ Gender (Ref: Male) } \\
\hline Female & 1.005 & .005 & $(.172)$ \\
\hline Other & 1.583 & .459 & $(.440)$ \\
\hline \multicolumn{4}{|l|}{ Marital status (Ref: Never married) } \\
\hline Cohabiting & .715 & -.336 & $(.262)$ \\
\hline Married & .778 & -.252 & $(.161)$ \\
\hline Formerly married & .929 & -.074 & $(.288)$ \\
\hline Any children & 1.059 & .057 & $(.266)$ \\
\hline Non-white & .919 & -.085 & $(.114)$ \\
\hline Bachelor's degree or higher & 1.427 & $.355^{* *}$ & $(.109)$ \\
\hline \multicolumn{4}{|l|}{ Employment status (Ref: Employed, full-time) } \\
\hline Employed, part-time & .960 & -.041 & $(.299)$ \\
\hline Unemployed & .626 & -.468 & $(.390)$ \\
\hline Not in labor force & .743 & -.297 & $(.154)$ \\
\hline Own home & 1.068 & .066 & $(.065)$ \\
\hline Financial situation worse than previous year & .684 & $-.379 * * *$ & $(.083)$ \\
\hline \multicolumn{4}{|l|}{ Political party (Ref: Liberal Party) } \\
\hline Conservative Party & .175 & $-1.744 * * *$ & $(.163)$ \\
\hline New Democratic Party & .620 & -.477 & $(.281)$ \\
\hline Other & .337 & $-1.087 * *$ & $(.348)$ \\
\hline \multicolumn{4}{|l|}{ Province/Region (Ref: Ontario) } \\
\hline Quebec & .935 & -.067 & $(.054)$ \\
\hline $\mathrm{BC}$ & 1.092 & $.088 * *$ & $(.033)$ \\
\hline Prairie provinces & 1.289 & $.254 * * *$ & $(.020)$ \\
\hline Atlantic provinces & 1.274 & $.242 * *$ & $(.080)$ \\
\hline COVID-19 expenses & 1.217 & .197 & $(.351)$ \\
\hline Informed about COVID-19 & 2.195 & $.786 * * *$ & $(.171)$ \\
\hline
\end{tabular}


This article has undergone peer review and been accepted for publication by the Canadian Public Policy/Analyse de politiques. Due to the importance of the subject matter, and the rapidly changing nature of the topic, the accepted version has been released. A final, copyedited and formatted version will be published at a later date.

Concerned about COVID-19

1.154

.143

Applied for CERB

1.467

$.383 * *$

(.138)

Pseudo R-Squared

.134

$* * * \mathrm{p}<.001, * * \mathrm{p}<.01, * \mathrm{p}<.05$

SOURCE: 2020 COVID-19 Response Survey of People with Disabilities and Health Conditions, N = 1027 adults

NOTES: Logistic regression models predicting probability of a positive view of the federal government COVID-19 response. Continuous

variables are mean centered. " $b$ " refers to logit model coefficients. Odds ratios can be obtained by exponentiating (b). Standard errors are in parentheses. Standard errors account for clustering by province/region. 
Table C4. Results from Ordered Logistic Regression Models Predicting Support for Federal Government's COVID-19 Response

\begin{tabular}{|c|c|c|c|}
\hline & \multicolumn{3}{|c|}{ Model 1} \\
\hline & OR & $\mathrm{b}$ & SE \\
\hline Physical disability & 1.383 & .324 & $(.183)$ \\
\hline Cognitive disability & .991 & -.009 & $(.215)$ \\
\hline Emotional disability & 1.323 & $.280 * * *$ & $(.064)$ \\
\hline Vision disability & 1.089 & .085 & $(.183)$ \\
\hline Hearing disability & .728 & -.317 & $(.252)$ \\
\hline Other disability & .723 & $-.324 * * *$ & $(.070)$ \\
\hline Asthma & 1.093 & .089 & $(.127)$ \\
\hline Cancer & 1.527 & .423 & $(.325)$ \\
\hline Chronic kidney disease & 1.583 & .459 & $(.285)$ \\
\hline Chronic respiratory or lung disease & .803 & -.219 & $(.625)$ \\
\hline Diabetes & 1.383 & .324 & $(.271)$ \\
\hline Hypertension & .983 & -.017 & $(.302)$ \\
\hline Obesity & 1.184 & .169 & $(.242)$ \\
\hline Immunocompromised & .725 & -.322 & $(.202)$ \\
\hline Heart disease & .952 & -.049 & $(.192)$ \\
\hline Age & 1.023 & $.022 *$ & $(.010)$ \\
\hline \multicolumn{4}{|l|}{ Gender (Ref: Male) } \\
\hline Female & 1.180 & .166 & $(.089)$ \\
\hline Other & 1.591 & .464 & $(.462)$ \\
\hline \multicolumn{4}{|l|}{ Marital status (Ref: Never married) } \\
\hline Cohabiting & .827 & -.190 & $(.188)$ \\
\hline Married & .869 & -.141 & $(.147)$ \\
\hline Formerly married & .961 & -.040 & $(.350)$ \\
\hline Any children & 1.064 & .062 & $(.177)$ \\
\hline Non-white & 1.087 & .083 & $(.065)$ \\
\hline Bachelor's degree or higher & 1.244 & $.219^{*}$ & $(.102)$ \\
\hline \multicolumn{4}{|l|}{ Employment status (Ref: Employed, full-time) } \\
\hline Employed, part-time & .948 & -.053 & $(.213)$ \\
\hline Unemployed & .543 & -.610 & $(.385)$ \\
\hline Not in labor force & .826 & -.191 & $(.122)$ \\
\hline Own home & 1.079 & .076 & $(.076)$ \\
\hline Financial situation worse than previous year & .692 & $-.369^{* * *}$ & $(.054)$ \\
\hline \multicolumn{4}{|l|}{ Political party (Ref: Liberal Party) } \\
\hline Conservative Party & .147 & $-1.914 * * *$ & $(.111)$ \\
\hline New Democratic Party & .584 & $-.537^{*}$ & $(.270)$ \\
\hline Other & .331 & $-1.106^{* * *}$ & $(.297)$ \\
\hline \multicolumn{4}{|l|}{ Province/Region (Ref: Ontario) } \\
\hline Quebec & .900 & $-.105^{* *}$ & $(.036)$ \\
\hline $\mathrm{BC}$ & 1.112 & $.107^{* *}$ & $(.036)$ \\
\hline Prairie provinces & 1.038 & .037 & $(.019)$ \\
\hline Atlantic provinces & 1.262 & $.232 * * *$ & $(.059)$ \\
\hline COVID-19 expenses & 1.033 & .033 & $(.211)$ \\
\hline Informed about COVID-19 & 1.971 & $.679^{* * *}$ & $(.154)$ \\
\hline Concerned about COVID-19 & 1.111 & .106 & $(.098)$ \\
\hline Applied for CERB & 1.495 & $.402 * * *$ & $(.054)$ \\
\hline
\end{tabular}


POLITIQUES

This article has undergone peer review and been accepted for publication by the Canadian Public Policy/Analyse de politiques. Due to the importance of the subject matter, and the rapidly changing nature of the topic, the accepted version has been released. A final, copyedited and formatted version will be published at a later date.

Cut 1

Cut 2

Pseudo R-Squared

.109

.

SOURCE: 2020 COVID-19 Response Survey of People with Disabilities and Health Conditions, $\mathrm{N}=1027$ adults

NOTES: Ordered logistic regression models predicting views of the federal government COVID-19 response. Continuous variables are mean centered. " $b$ " refers to ordered logit model coefficients. Odds ratios can be obtained by exponentiating (b). Standard errors are in parentheses. Standard errors account for clustering by province/region. 


\section{References}

Fredriksen-Goldsen, K. I., Kim, H. J., \& Barkan, S. E. 2012. Disability among lesbian, gay, and bisexual adults: Disparities in prevalence and risk. American Journal of Public Health, 102(1): e16-e21.

Morris, S., Fawcett, G., Brisebois, L., \& Hughes, J. 2018. A demographic, employment and income profile of Canadians with disabilities aged 15 years and over, 2017. Statistics Canada no. 89654-X201800.

Statistics Canada. 2020a. Census profile, 2016 Census. Statistics Canada no. 98-316-X2016001. https://www12.statcan.gc.ca/census-recensement/2016/dp-pd/prof/index.cfm?Lang=E

Statistics Canada. (2020b.) Education Highlight Tables, 2016 Census. Statistics Canada Catalogue no. 98-402-X2016010. http://www12.statcan.gc.ca/census-recensement/2016/dp-pd/hltfst/edu-sco/index-eng.cfm

Waite, S., \& Denier, N. 2019. A Research note on Canada's LGBT data landscape: Where we are and what the future holds. Canadian Review of Sociology/Revue canadienne de sociologie, 56(1): 93-117. 